\title{
Localization and Development of Nerve Growth Factor-Sensitive Rat Basal Forebrain Neurons and Their Afferent Projections to Hippocampus and Neocortex
}

\author{
Sookyong Koh ${ }^{1}$ and Rebekah Loy ${ }^{2}$ \\ 'Department of Neurobiology and Anatomy and 'Division of Neurosurgery, University of Rochester School of Medicine, \\ Rochester, New York 14642
}

In order to understand further the role of NGF in the development of NGF-sensitive basal forebrain neurons and their afferent connections to the hippocampus and neocortex, we have used monoclonal antibody $192 \mathrm{lgG}$ to detect and localize NGF receptors immunocytochemically in the developing rat brain. NGF receptor immunoreactivity (NGF-RI) is first visible at embryonic day 13 (E13) in the ventrolateral telencephalic wall and follows a caudal-to-rostral gradient in its initial appearance. NGF-RI neuronal number and neuropil staining undergo substantial increases before birth, and extensive dendritic growth and increases in perikaryal size continue during the first 3 weeks of postnatal life. This growth and cellular differentiation, however, is followed in the fourth postnatal week and later by an apparent decrease in dendritic arborization and $\mathbf{5 0} \%$ shrinkage in the size of perikarya. Initial NGF-RI fiber outgrowth from immature basal forebrain neurons directed toward appropriate target fields is observed as early as E15. The formation of a laminar pattern by septal axons in the hippocampal terminal fields and invasion of NB afferents into the cortex occur postnatally over a protracted time. In the hippocampus, NGF-RI is initially diffusely distributed, and wide bands of immature granule and pyramidal cells are almost devoid of immunoreactive fibers; however, with maturity, septal axon terminals become concentrated in narrow zones closely associated with the cellular layers. In the neocortex, early-arriving basal forebrain afferents accumulate in the intermediate zone underneath the darkly immunoreactive subplate before they enter the cortex. Dense subplate and translently present, radially aligned fiber staining completely disappear in later postnatal week and are gradually replaced by specific axonal and terminal staining associated with NB afferents. The expression of NGF receptor in the subplate zone at the time afferents arrive and its subsequent disappearance with the specific terminal formation suggest that NGF receptor and concomitant accumulation of NGF in the subplate may act

\footnotetext{
Received Aug. 1, 1988; revised Dec. 29, 1988; accepted Feb. 14, 1989.

We wish to thank Dr. E. M. Johnson, Jr., for providing the purified $192 \mathrm{IgG}$. We also wish to thank Ms. Nancy Dimmick and Ms. Dorothy Herrera for photographic assistance and Ms. Diane Alesi and Ms. Dorothy Heyer for technical assistance. This work was supported by PHS NRSA MH-09541 (S.K.) and by grants (R.L.) from the Dysautonomia Foundation and NIH NS 25169.

Correspondence should be addressed to Sookyong Koh, Department of Neurobiology and Anatomy, Box 603, University of Rochester School of Medicine, 601 Elmwood Avenue, Rochester, NY 14642.

Copyright (C) 1989 Society for Neuroscience 0270-6474/89/092999-20\$02.00/0
}

as a temporary target for the early-arriving basal forebrain afferents; ingrowing afferents may then be guided by radially oriented NGF-RI fibers to proper synaptic sites.

A remarkable feature of developing neurons is their ability to extend processes over a considerable distance and form highly precise and stereotyped patterns of connections. While there is no consensus on how growing axons find appropriate targets and make specific synaptic contacts, available evidence indicates that some form of recognition and competitive interaction occurs at the level of the target site. Following spinal cord reversal (Lance-Jones and Landmesser, 1980) or eye rotation (Sperry, 1963), for example, displaced motor neurons and retinal neurons change their growth cone trajectories to innervate the original targets. Limb bud ablation or implantation of an extra limb bud in early chick embryogenesis induces a dramatic decrease or increase, respectively, of neurons innervating the limb (Hamburger, 1934, 1939), clearly demonstrating target-dependent neuronal survival. During normal development, neurons as well as axons and synaptic terminals are overproduced and subsequently eliminated, apparently as a result of a competition between different afferents for a limited supply of target-derived substance (Cowan et al., 1984). Indeed, it is the discovery and study of a diffusible chemical substance present in neuronal targets, nerve growth factor (NGF), that have helped unravel the role of target-derived macromolecules on directed axonal outgrowth, cell survival, neuronal differentiation, and maintenance of neuron-specific properties.

NGF appears to act on responsive cells at 2 separate sites. Present locally at the growth cone, NGF can affect the directionality of neurite outgrowth (Gundersen and Barret, 1979) and maintenance of terminal arborization (Campenot, 1977). Longer-term trophic effects of NGF are thought to be mediated in the cell body, through a process involving the binding of NGF to high-affinity receptors at the nerve terminals, then by internalization and retrograde transport of the receptor-ligand complex to the target perikarya (Thoenen and Barde, 1980). While it is not clear if the apparent chemotropism toward high concentrations of NGF and local neurite development are also receptor-mediated responses, in chick sensory neurons the appearance of high-affinity NGF receptors during ontogenesis coincides with the first fiber outgrowth response to NGF (Herrup and Shooter, 1975). Further, a decrease in the number of specific NGF receptor with age correlates with the lack of NGF effects in cultures of these ganglion cells at embryonic day (E) 16 or later (Herrup and Shooter, 1975). 
Recent works have begun to elucidate the role of NGF as an endogenous trophic factor for the development of basal forebrain cholinergic neurons. NGF receptor protein and mRNA are present in basal forebrain neurons, and their expression is developmentally regulated (Buck et al., 1987; Yan and Johnson, 1987, 1988). Also, relatively high levels of NGF and its mRNA are present in developing brain, and their expression in cholinergic basal forebrain nuclei, and target areas, hippocampus and neocortex, is well correlated with the increase in choline acetyltransferase (ChAT) activity during postnatal development (Large et al., 1986). That differentiation of basal forebrain neurons may be regulated by NGF is further supported by the effects of exogenous NGF administration in vivo and in vitro. Intraventricular injection of NGF into neonatal rats induces ChAT activity in septum, nucleus basalis, and their projection areas (Gnahn et al., 1983; Mobley et al., 1986); and fetal septal neurons in culture respond to NGF by an increase in ChAT activity (Hefti et al., 1985). A possible role of NGF in axonal guidance and selective stabilization of terminal arbors of central cholinergic neurons has been suggested by the observation that acetylcholinesterase (AChE)-positive fibers from septal explants grow selectively to cocultured hippocampal and cortical slices but not toward tissues that normally do not receive cholinergic afferents or producc NGF, such as hypothalamus and substantia nigra (Gähwiler and Hefti, 1984). Moreover, this directed fiber growth from septum to hippocampus, but not a diffuse, nondirected outgrowth, is selectively promoted by the addition of NGF into the culture medium (Gähwiler et al., 1987).

In order to understand further the role of NGF in the development of NGF-sensitive basal forebrain neurons and their afferent connections to the hippocampus and neocortex, we have used monoclonal antibody $192 \mathrm{IgG}$ to detect and localize NGF receptors immunocytochemically in the developing rat brain. We specifically wanted to correlate the time course of appearance of NGF receptor (1) with synthesis of NGF and (2) with neuronal migration, axonal outgrowth, and functional synapse formation in the target tissues.

\section{Materials and Methods}

Materials. Monoclonal antibody $192 \mathrm{IgG}$, mouse anti-rat NGF receptor (Chandler et al., 1984), was characterized (Taniuchi and Johnson, 1985) and provided by E. M. Johnson (Washington University, St. Louis). Affinity-purified biotinylated horse anti-mouse IgG (preabsorbed to remove cross-reactivity for rat IgG), normal horse serum (NHS), and the $A B C$ peroxidase kits were purchased from Vector Lab (Burlingame, CA). Other chemicals were obtained from Sigma (St. Louis, MO).

Animals. Timed-pregnant Long-Evans rats were purchased from Charles River Labs (Wilmington, MA). Embryos were removed from the anesthetized mothers and crown-rump length (CRL) measured to assess the variation in the size of embryos and to assign to each embryo a gestational age corresponding to the range of CRLs for each gestational day. The day of insemination is designated as EO and the day of birth as postnatal day $0(\mathrm{P} 0)$. A total of 107 animals at the following ages were processed and examined in this study: E12 $(\mathrm{CRL}=5-7 \mathrm{~mm})$, E13 $(\mathrm{CRL}=8-10 \mathrm{~mm}), \mathrm{E} 14(\mathrm{CRL}=12 \mathrm{~mm}), \mathrm{E} 15(\mathrm{CRL}=13-15 \mathrm{~mm})$, E16 $(\mathrm{CRL}=15-17 \mathrm{~mm}), \mathrm{E} 17(\mathrm{CRL}=17-20 \mathrm{~mm}), \mathrm{E} 18(\mathrm{CRL}=21-$ $25 \mathrm{~mm}), \mathrm{E} 19-\mathrm{E} 21$ (CRL = 25-40 mm), P0, P1, P2, P3, P4, P5, P6, P7, P8, P9, P10, P15, P17, P21, P23, P30. Five male and female adult rats approximately $250 \mathrm{gm}$ were also included in the study.

Tissue preparation. Embryonic tissues were immersion fixed for $6 \mathrm{hr}$ in ice-cold $1-4 \%$ paraformaldehyde in $0.1 \mathrm{M}$ phosphate buffer, $\mathrm{pH} 7.4$, followed by overnight immersion in the same fixative containing $20 \%$ sucrose. E12 and E13 embryos were fixed whole; older embryos were decapitated, and the brains were removed for fixation. Postnatal animals were anesthetized with $50 \mathrm{mg} / \mathrm{kg}$ sodium pentobarbital (i.p.) and perfused transcardially with PBS (0.1 $\mathrm{m}$ sodium phosphate, $\mathrm{pH} 7.2$, con- taining $0.9 \%$ sodium chloride), followed by buffered $4 \%$ paraformaldehyde. The brains were removed and postfixed in buffered $4 \%$ paraformaldehyde containing sucrose overnight. For fetuses at E12E15, $30 \mu \mathrm{m}$ cryostat sections were cut, thaw-mounted onto slides, and stained on slides. For older animals, $50 \mu \mathrm{m}$ sliding microtome brain sections were cut, and every third section was collected and processed free-floating.

Immunocytochemistry. The specificity of monoclonal antibody 192 IgG for rat NGF receptor has been tested previously (Taniuchi and Johnson, 1985; Yan and Johnson, 1988). Coronal, horizontal, or sagittal sections were processed for immunocytochemistry using the avidinbiotin-peroxidase (ABC) method with or without nickel(II) sulfate intensification (Hancock, 1982). The sections were preincubated directly for $30 \mathrm{~min}$ with $0.1 \%$ Triton X-100 and $30 \mathrm{~min}$ with $4 \% \mathrm{NHS}$ at room temperature, then incubated for $24-48 \mathrm{hr}$ at $4^{\circ} \mathrm{C}$ with $2 \mu \mathrm{g} / \mathrm{ml}$ of 192 $\mathrm{IgG}$ in $10 \mathrm{~mm}$ PBS $/ 1 \%$ NHS. The sections were then washed 3 times in $10 \mathrm{~mm}$ PBS, $10 \mathrm{~min}$ each at room temperature, and incubated overnight at $4^{\circ} \mathrm{C}$ with $1: 150$ affinity-purified biotinylated horse anti-mouse $\mathrm{IgG}$ in $10 \mathrm{mM} \mathrm{PBS} / 1 \% \mathrm{NHS}$. When quenching of endogenous peroxidase activity was required for immersion-fixed tissue, sections were treated with $0.3 \% \mathrm{H}_{2} \mathrm{O}_{2}$ in $10 \mathrm{~mm}$ PBS for $30 \mathrm{~min}$ at room temperature after incubation with biotinylated secondary antibody. The sections were then washed, incubated for $3 \mathrm{hr}$ at room temperature in an avidinbiotin-peroxidase complex. Following several washes in PBS, the sections were reacted for $8 \mathrm{~min}$ in $0.05 \% 3,3^{\prime}$-diaminobenzidine and $0.01 \%$ hydrogen peroxide. Control sections were run with no primary antibody.

\section{Results}

$N G F$ receptor-immunoreactive ( $N G F-R I$ ) basal forebrain neurons in adult rat

In the adult rat, large multipolar basal forebrain neurons are immunoreactive for NGF receptor throughout the medial septal nucleus (MS), vertical (VDB), and horizontal limbs of the diagonal band of Broca (HDB) and the nucleus basalis magnocellularis (NB) (Fig. 1). The cell bodies are intensely immunoreactive, with tapering, varicose dendrites forming a densely stained neuropil within each nuclear area (Fig. 2). While NGFRI neurons comprise a contiguous group of cells without sharp borders between one nucleus and the next, each nucleus can be distinguished by characteristic cytological features: NB is characterized by distinct clusters of large somata interwoven by a confluence of dendritic processcs (Fig. 2D); MS/DBV consists of small-sized, bipolar neurons, mainly of oval or fusiform shapes; and HDB contains mostly larger, round-shaped multipolar neurons (compare Fig. 2, $A, C$ ). From MS rostrally to NB caudally, dendritic arbors become progressively more elaborate and the perikaryal size increases (mean cross sectional area $\left(\mu \mathrm{m}^{2}\right) \pm \mathrm{SD}$ : $\mathrm{MS}=129 \pm 54, n=44 ; \mathrm{VDB}=156 \pm 50, n=57 ; \mathrm{HDB}=$ $192 \pm 88, n=60 ; \mathrm{NB}=242 \pm 78, n=57)$. Axons of the MS/ $\mathrm{VDB}$ and $\mathrm{HDB} / \mathrm{NB}$ cells are immunoreactive in the cortical and hippocampal terminal fields, and throughout their respective courses in the fimbria, supracallosal stria and dorsal fornix, and the cingulum/external capsules. There was no staining in either the adult or developing brains in the absence of primary antibody.

\section{Development of NGF-RI basal forebrain neurons}

Onset of NGF receptor expression. NGF-RI is first visiblc at E13 in rat basal forebrain. Faint immunoreactive cell profiles are detectable in the intermediate zone of the ventrolateral telencephalic wall (Figs. 3, E13B; $5 H$ ). A more rostrally located dorsomedial cell group can first be identified at E15 (Figs. 3, $\mathrm{E} 15 \mathrm{~A} ; 5 \mathrm{C})$. NGF-RI striatal neurons are detected later at E17 as individual cells or small clusters of cells.

Nuclear formation and cellular distribution. Beginning with the initial expression of NGF receptor, NGF-RI neurons form 


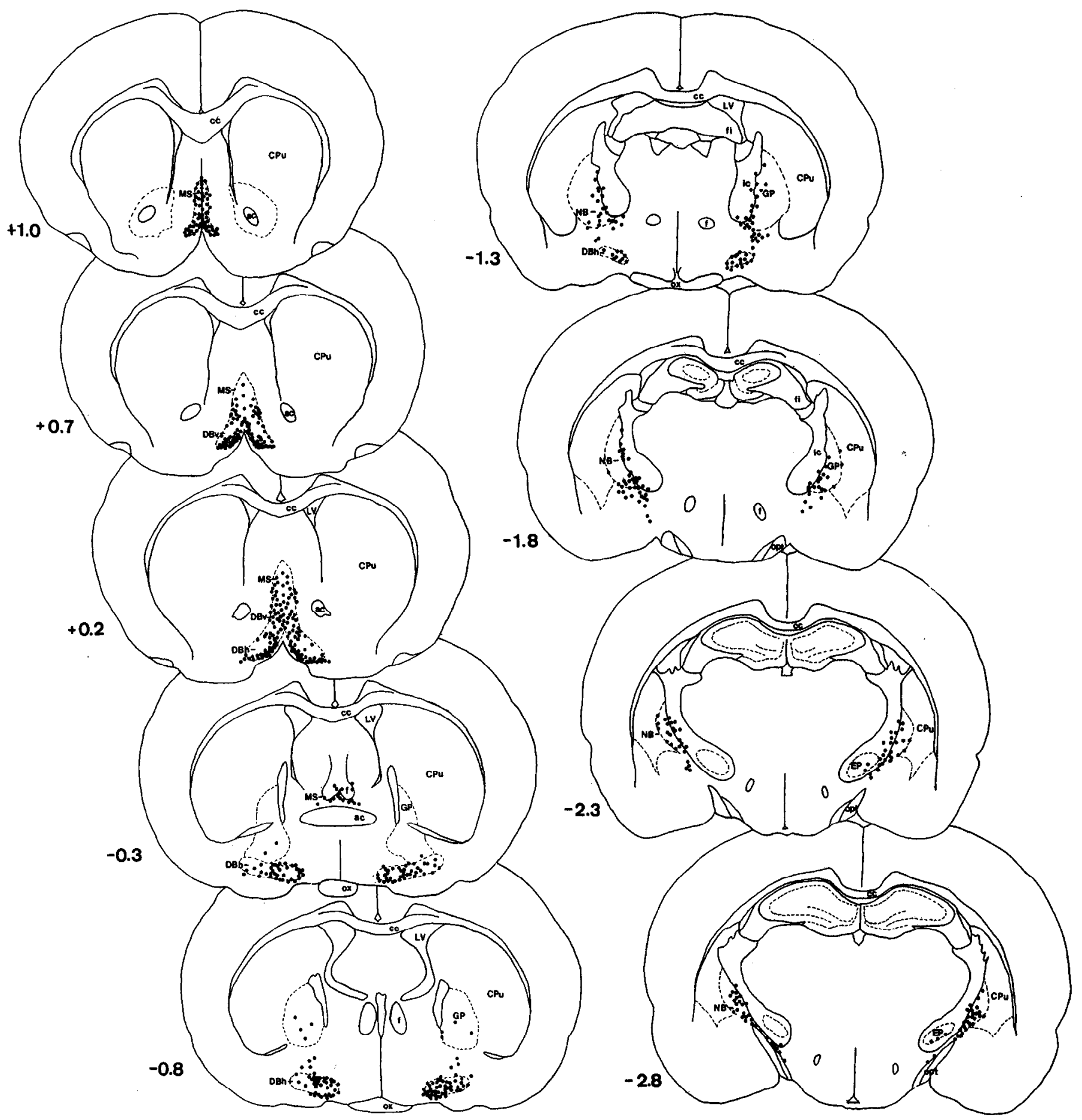

Figure 1. Distribution of NGF-RI basal forebrain neurons in the adult rat. NGF receptor-positive neurons comprise a contiguous group of cells associated with medial septal nucleus $(M S)$, vertical $(D B v)$, and horizontal $(D B h)$ limb of the diagonal band of Broca, nucleus basalis $(N B)$, lateral preoptic area, ventral globus pallidus $(G P)$, and substantia innominata. Numbers indicate the rostrocaudal coordinates from bregma. Each dot represents 2 or more neurons. $a c$, anterior commissure; $c c$, corpus callosum; $C P u$, caudate putamen; $E P$, entopeduncular nucleus; $f$, fornix; $f$, fimbria; $i c$, internal capsule; $L V$, lateral ventricle; opt, optic tract; $o x$, optic chiasm.

loose aggregations. Cells of the first-recognized ventrolateral cell group (NB precursor) apparently extend both caudally and rostrally between E13 and E15 (Fig. 3, E13-E15), and the rostral extension establishes the ventromedial cell group (DB precursor) by E15 (Fig. 3, E15B). At this time, the most rostrally located, dorsomedial cell group (MS precursor) appears close to the ventricular zone (Fig. 3, E15A) and caudally forms a continuum with the ventromedial cell group (Fig. 3, E15B, $C$; E16B, C). An adult-like cell distribution is already apparent at E17, as the NGF-RI neurons become quite numerous and form well-defined nuclei (Fig. 5D). Some MS neurons, however, are still placed laterally, close to the ventricular zone (Fig. 5D); and the HDB and NB occur as one continuous nucleus at the ventrolateral surface of the forebrain (Fig. $5, J, K$ ). 

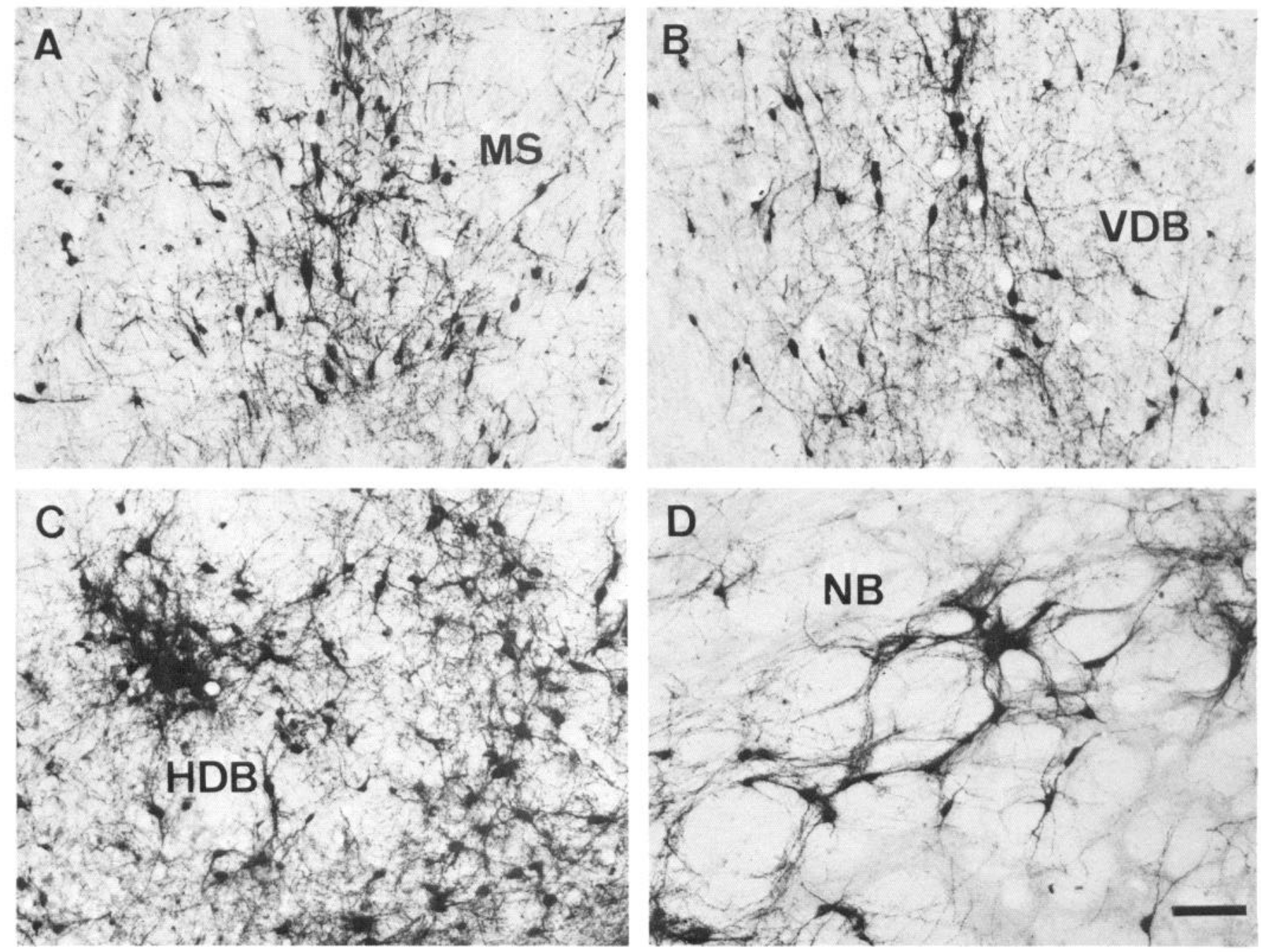

Figure 2. Coronal sections from an adult rat showing the characteristic morphology and interneuronal organization of NGF-RI neurons in the various components of the basal forebrain complex in the adult rat. $A$, MS at $0.3 \mathrm{~mm}$ caudal to bregma $(-0.3 \mathrm{in}$ Fig. 1$)$. $B$, VDB at +0.2 . $C$, HDB and magnocellular preoptic nucleus at $-0.8 . D$, NB along the ventromedial edge of the globus pallidus. Note progressively more elaborate dendritic processes and apparent increase in cell soma size from $A$ through $D$ (see text for the quantitation of cross-sectional area). Scale bar, $100 \mu \mathrm{m}$.

By P1, NGF-RI neurons show a mature pattern of cellular distribution associated with MS, VDB, HDB, and NB (Fig. 4). In addition, small striatal interneurons are clearly immunoreactive for NGF receptor. Their topography (Fig. 4, upper panel, smaller-sized dots in $\mathrm{CPu}$ ) and cellular morphology are similar to AChE-positive neurons at this age (compare Fig. 4, $A, B$ ). NGF-RI striatal neurons are no longer detectable by P10 and are only rarely encountered in the adult rat striatum.

Cellular differentiation and maturation. Initially, NGF-RI neurons are few in number, and small, immature cell profiles are rimmed by rather diffuse immunoreactive products (Fig. 5, $B, H, I)$. At E15, individual immunoreactive cells within a cluster become clearly discernible, and short neurites can occasionally be seen, especially in the NB region (Fig. 6A). Following the caudal-to-rostral gradient of the initial appearance of NGF-RI neurons, there also appears to be a caudal-to-rostral progression of neuronal maturation. This is most apparent at E16 (compare Fig. 5, $C$ and $J$ ): caudally located NB/HDB nuclei consist of numerous neurons distinctly outlined by NGF-RI, whereas rostrally located MS/DB nuclei contain diffuse and less intensely staining aggregations of cell profiles. Between E15 and
E17, NGF-RI neuronal number and neuropil staining undergo substantial increases (Fig. 5, $A-D, H-K$ ). By E19-20 (2 d before birth), the neuronal organization resembles that of fully differentiated nuclei: clusters of HDB neurons form characteristic oval-shaped nuclei around hollow, cell-free areas; and somata of NB neurons are interconnected by dendritic plexi, forming what looks like a neuronal syncytium (Fig. $6 B$ ). It is only at birth, however, that extensive dendritic growth is observed: A plexus of cellular processes almost obscures the yet-immature and small perikarya at P1 (Fig. 6C).

Profuse dendritic ramification, as well as an apparent increase in perikaryal size, continues during the first 3 weeks of postnatal life (Fig. 6, $C-E$ ). By P10, large multipolar NGF-RI neurons have the appearance of characteristic projection neurons, with ovoid or triangular soma and long, spiny dendritic plexi (Fig. $7 B$ ). This growth and cellular differentiation, however, is followed in the fourth postnatal week and later by an apparent decrease in dendritic arborization and shrinkage of perikarya (compare Figs. 5, $M, N$ and 7, $C, D$ ). This qualitative impression of an increase and subsequent decrease in soma size is confirmed by quantitative measurement of the cross-sectional area of NGF- 
E 13
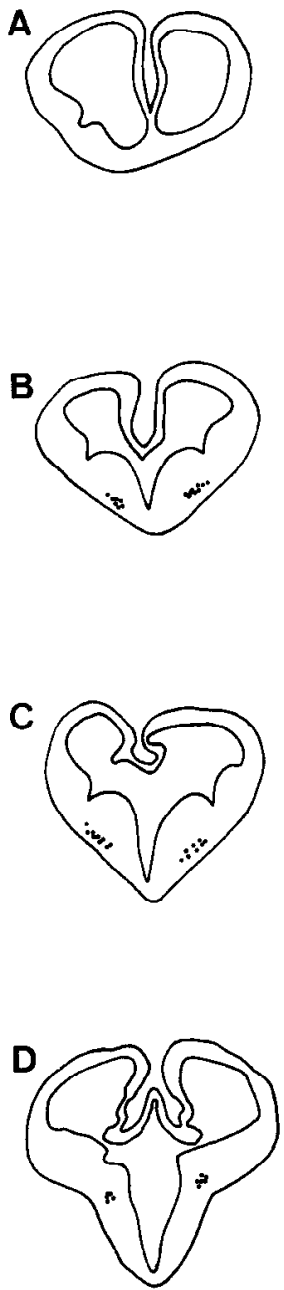

E 14
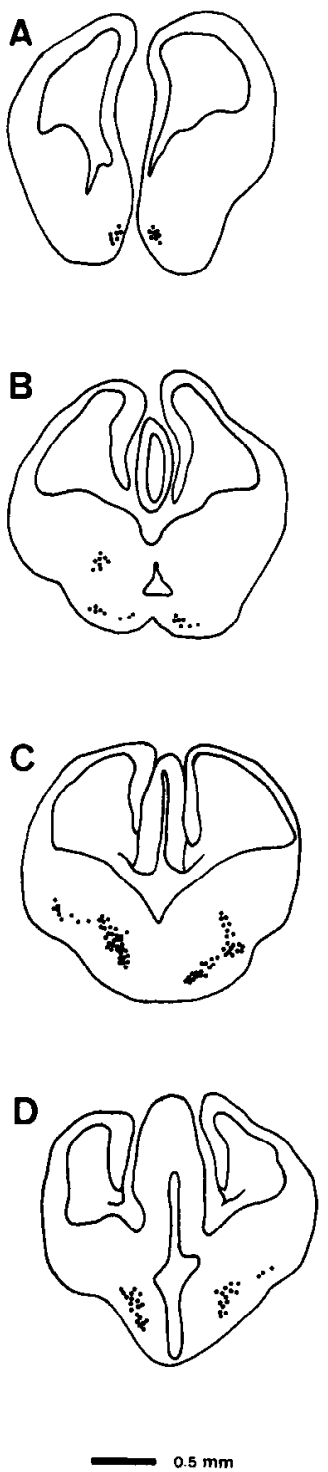

E 15
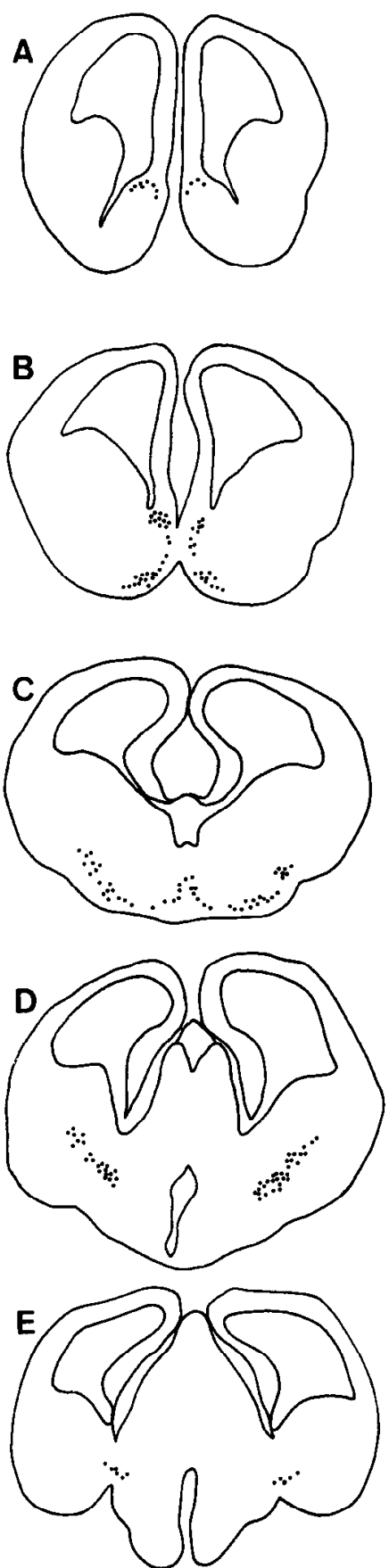

E 16
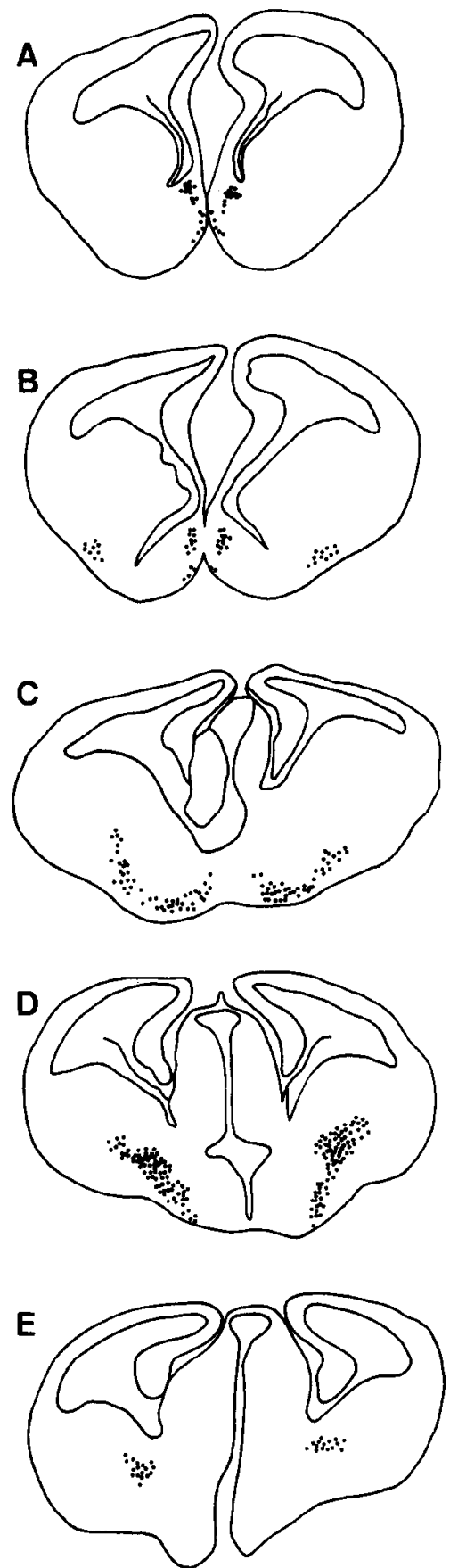

Figure 3. Nuclear formation and cellular distribution of NGF-RI basal forebrain neurons during prenatal period. Each dot represents one or more cells at that location. Ventromedial cell group (NB precursor) is first recognized at E13 ( $E 13 B$ and $C$ ), while dorsomedial cell group appears later, at E15, close to the ventricular zone $(E 15 A)$. Initially few at E13, NGF-RI neuronal numbers increase progressively from E13 through E16.

RI NB neurons in the substantia innominata (SI) region from E15 through adult. Figure 10 shows a steep, linear increase in cross-sectional area from E15 to P15, and an abrupt fall to near adult value by P30.

\section{Target arrival of basal forebrain afferents}

Septohippocampal projection. The embryonic hippocampus is identified as a strip of tissue oriented vertically along the medial surface of the forebrain, adjacent to the lateral ventricle (Stensaas, 1967). Using NGF receptor immunocytochemistry, the hippocampal anlage can be positively identified as early as E14 by the presence of radially oriented NGF-RI fibers which span it (Fig. 8A). At E16, with the ingrowth of septal axons and formation of the fimbria, the radial hippocampal staining is lost from the intermediate and marginal zones (Fig. $8 B$ ), and it is no longer present at E17 or later (Fig. 8D). 


\section{P 1}
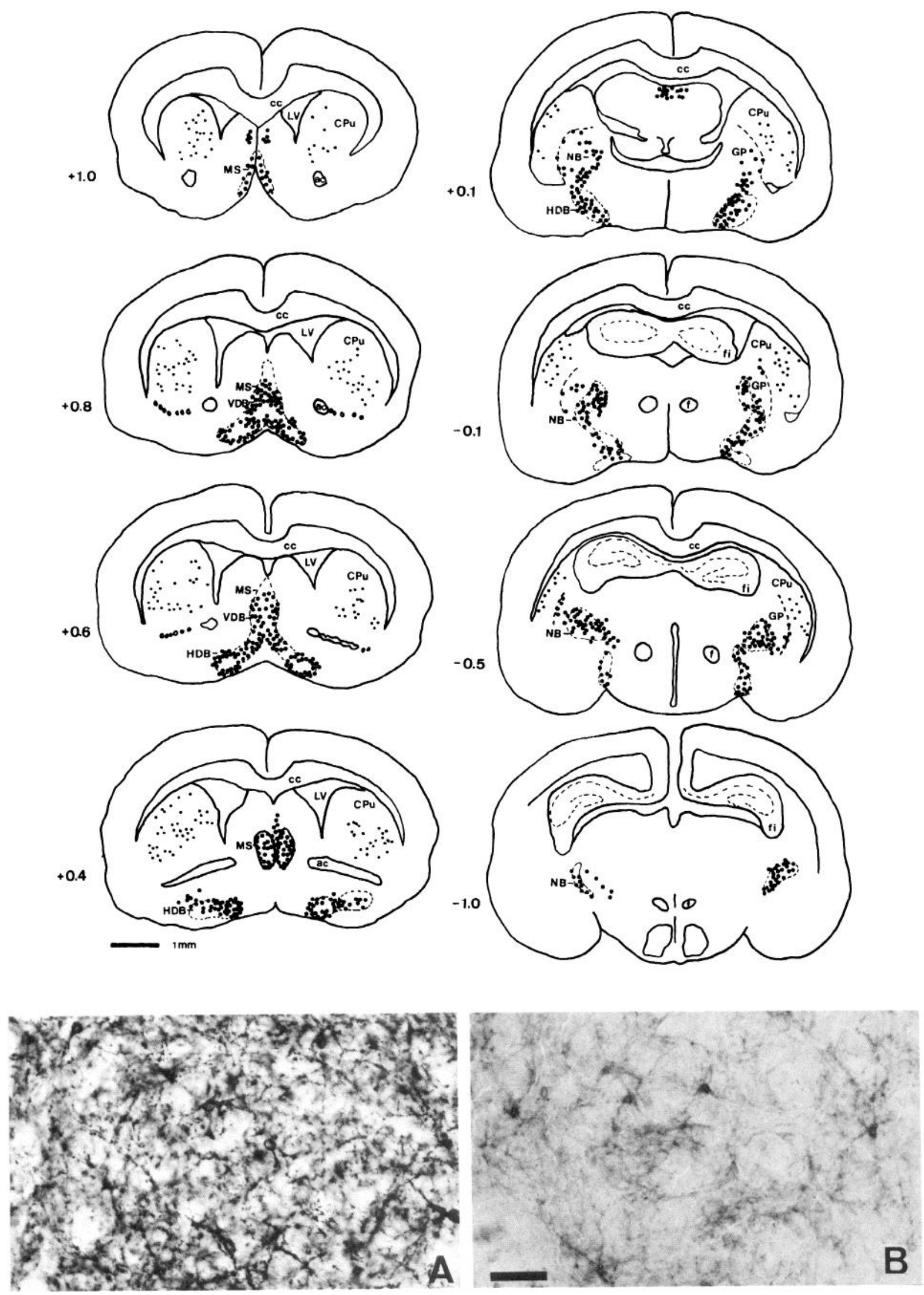

Figure 4. Distribution of NGF-RI neurons at P1. Numbers indicate rostrocaudal coordinates from bregma. Each dot represents 2 or more neurons. NGF-RI striatal neurons are drawn in smaller dots to reflect their smaller size compared to basal forebrain neurons. $A$, AChE staining of striatal interneurons. $B, 192 \mathrm{IgG}$ immunocytochemical staining of striatal interneurons at a corresponding level to the section in $A$ showing their morphological resemblance to AChE-positive neurons. Scale bar, $50 \mu \mathrm{m}$. 
Initial axonal outgrowth from immature MS/VDB neurons is first observed as early as E15, with more definitive axonal staining appearing at E16. The NGF-RI fiber bundles traverse dorsorostrally from the DB toward the hippocampal anlage (Fig. $8 C$ ). At this stage, the distance traveled by the growing axons is quite short as a result of the juxtaposition of the immature septum to the hippocampus (Fig. 8B). At E17, immunoreactivity is dense in the fimbria; coarse NGF-RI fibers can be traced into the intermediate zone of the developing Ammon's horn and into the dentate gyrus anlage (Fig. $8 D$ ). At P1, axons arising from MS/VDB are immunoreactive throughout their course in the fimbria and dorsal fornix. Immunoreactive fibers are also present around the genu and splenium of the corpus callosum, and within the spracallosal stria and cingulum bundle, from which they enter the medial frontal and cingulate cortices and caudal hippocampus (Fig. 8E).

Septal axons are also immunoreactive in the hippocampal terminal fields by P1 (Fig. $9 A$ ). NGF-RI is diffusely laminated, with moderately heavy fiber staining occurring in the vicinity of stratum granulosum of the suprapyramidal limb of the dentate gyrus and around strata oriens and radiatum of the hippocampus proper. The wide bands of immature granule and pyramidal cells are almost devoid of immunoreactive fibers. In the suprapyramidal limb of the dentate gyrus, there is an intensification of staining in the lateral margin of stratum granulosum at its border with stratum radiatum of the $\mathrm{CA} 3$ hippocampal subfield (Fig. 9A). By the end of the first postnatal week, cell layers clear of axonal termination become more prominent, and the hilus and stratum radiatum contain increased numbers of immunoreactive fibers. Also, the infrapyramidal limb of the dentate gyrus becomes visible and as densely stained as the suprapyramidal limb (Fig. 9, $B, C$ ). Overall, the distribution of NGF-RI fibers starts to resemble the adult pattern, as the staining is more closely associated with the cellular layers. The mature pattern is achieved by P30. Fine, varicose immunoreactive fibers are mainly concentrated in the innermost stratum oriens very closely associated with pyramidal cell soma and proximal dendrites. Relatively light staining is present in outer two-thirds of stratum oriens, CA3 stratum lucidum and in a thin band of the stratum lacunosum-moleculare. In the dentate gyrus, NGFRI fibers accumulate just above and below the stratum granulosum and innervate with moderate density the stratum moleculare and hilus (Fig. 9D). Thus, initially diffuse septal axon terminals become concentrated immediately supra- and subjacent to narrow cellular layers.

Basalocortical projection. At its earliest developmental stage, the neocortex (pallium) consists of a pseudostratified epithelium. By E13-14 in rat, a thin strip of marginal zone appears beneath the meningeal surface, becoming distinct from the ventricular zone. At E15, a spatial gradient in the development of the cortical plate is evident, as the more lateral and anterior regions (to the left of Fig. 10A) develop earlier than the occipital pole (to the right). Prior to the development of the cortical plate, dense immunoreactivity spans the marginal zone; with the emergence of the cortical plate, additional NGF-RI becomes concentrated in a narrow zone at the base of the cortical plate and just below in the superficial part of the intermediate zone, in what has been referred to as the subplate (Luskin and Shatz, 1985) (Fig. 10A). While it cannot be determined definitively without electron microscopic work, it appears that immunoreactive products in the subplate zone are deposited in the neuropil surrounding the circular, unstained cellular elements rather than in the cells themselves. At this age (E15), axons from NB neurons form faintly visible bundles of fibers directed toward the developing neocortex, and as NGF-RI afferents arrive in the cortex, they accumulate in the intermediate zone underneath the darkly stained subplate (Fig. 10A).

By E17, densely immunoreactive fascicles of fibers sweep laterally through SI and the ventral part of the caudate-putamen to enter the cortex of the lateral wall of the hemisphere (Fig. $11 A$ ). Fibers from the HDB and NB can also be seen directly entering paleocortical areas at the base of the brain (Fig. 12). In addition, beginning at E17, intensely NGF-RI fibers associated with the thalamocortical afferents course from the ventrobasal and geniculate nuclei, through the thalamic radiations and into the intermediate and subplate zones of specific sensory cortical areas. NGF-RI basalocortical afferents appear arrested at the densely immunoreactive subplate zone, superficial to the thalamic afferents, as no ingrowth into the cortical plate is observed (Fig. 10B). At E19, the fasciculation of NGF-RI fibers is more apparent (Fig. $11 B$ ), and with continued neuronal proliferation and the addition of neurons into the cortical plate, NGF-RI intrinsic to the subplate zone moves closer to the ventricular surface (Fig. 10D). Beginning at P1, radially oriented, fine, fiberlike projections of immunoreactivity emanate from the densely stained subplate zone and extend up toward the pial surface (Fig. 10E). Both radially aligned and thalamocortical-associated staining become weaker in intensity at P5 (Fig. 10F) and disappear by the second postnatal week. Also, in accordance with the transient presence of the subplate zone, NGF-RI in this region, which is seen throughout the entire cortical surface during embryonic life, completely disappears in later postnatal weeks (see Fig. 10F). During this elimination of radial and subplateassociated staining, there is a gradual increase in specific axonal and terminal staining associated with NB afferents. The profuse outgrowth of axons from the basal forebrain neurons and their invasion of the cortical layers is most visible during the first postnatal week (Fig. 12, C,D); thereafter, the intensity and amount of fiber staining gradually diminishes, leaving at maturity a fine, varicose fiber network in the external capsule and in the cortical terminal region, particulary in cingulate, piriform, perirhinal, and entorhinal cortices.

\section{Discussion}

\section{$N G F$ sensitive neurons in rat basal forebrain}

NGF-RI is localized in adult rats to magnocellular basal forebrain neurons and to their terminals in the neocortex and hippocampus, as previously reported (Springer et al., 1987; Dawbarn et al., 1988). As in the primate (Kordower et al., 1988; Schatteman et al., 1988), the morphology of NGF-RI neurons in the various components of the basal forebrain complex closely resembles ChAT- or AChE-positive neurons in the corresponding areas (Bigl et al., 1982; Armstrong et al., 1983; Satoh et al., 1983; Sofroniew et al., 1987), and mapping of NGF-RI neurons throughout the rostrocaudal extension of the rat basal forebrain (Fig. 1) reveals a striking correspondence to the distribution of ChAT-positive neurons (Armstrong et al., 1983; Satoh et al., 1983; Semba and Fibiger, 1988).

One exception to the coexistence of NGF-RI and cholinergic forebrain neurons is the striatal interneuron, which lacks NGF$\mathrm{RI}$ in adult rats. Receptor autoradiography using iodinated NGF does, however, detect NGF binding sites in rat striatum jointly distributed with AChE activity (Richardson et al., 1986; Raivich and Kreutzberg, 1987). Since these neurons do express NGF- 


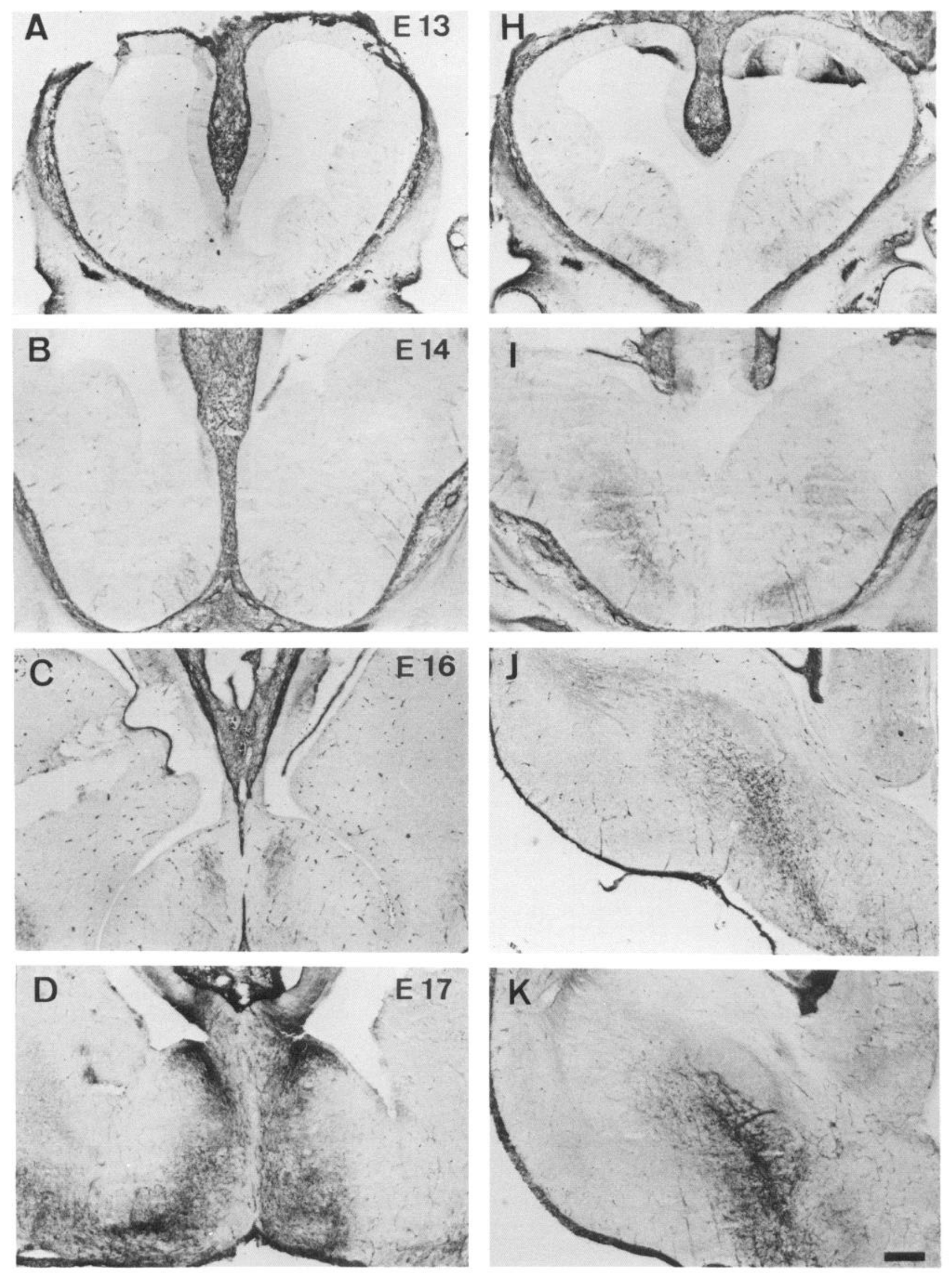



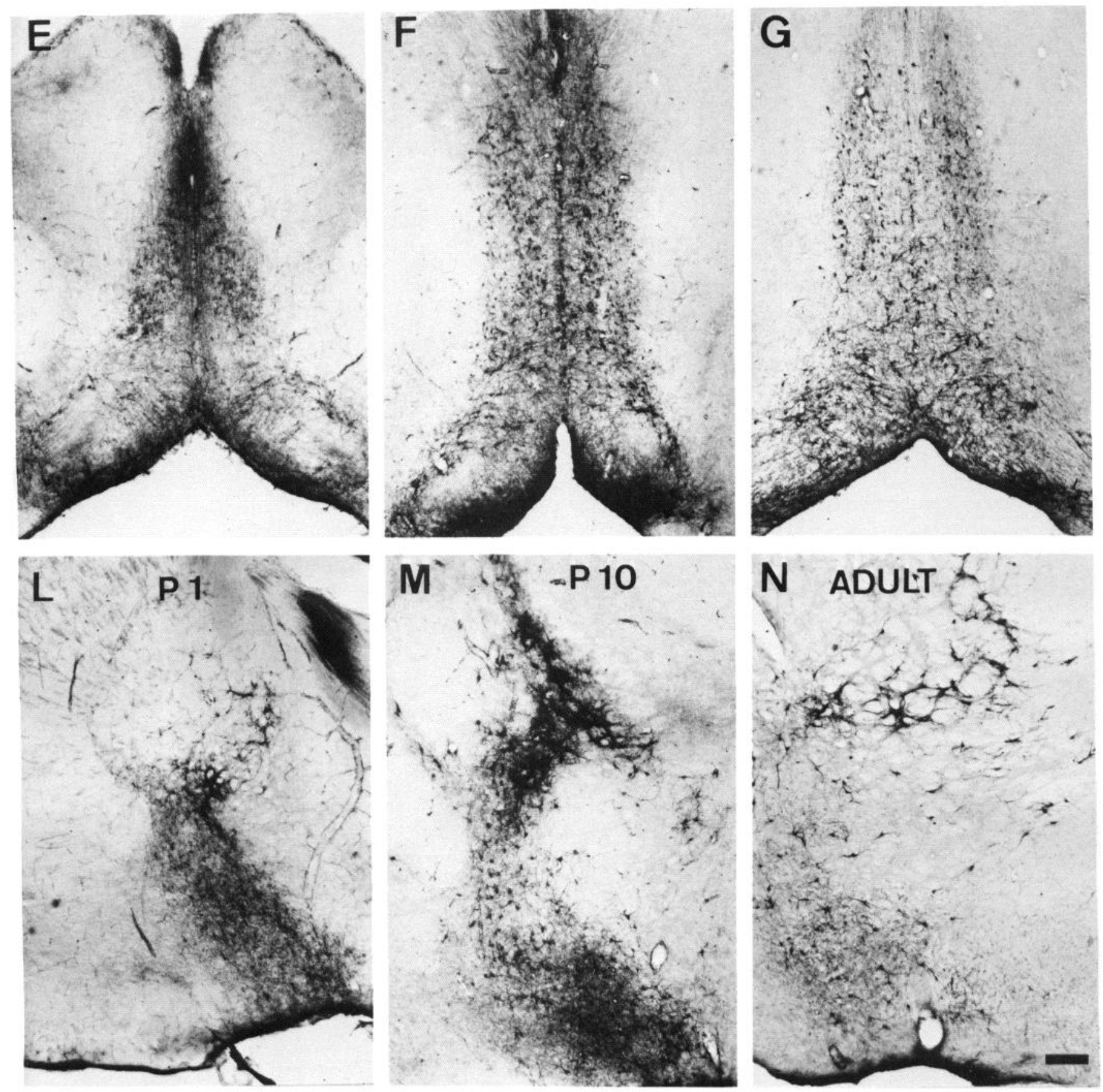

Figure 5. Pre- and postnatal development of NGF-RI basal forebrain nuclei. $A-G, \mathrm{MS} / \mathrm{DB} ; H-M$, NB/HDB. Note caudal-to-rostral progression of initial appearance and neuronal maturation by comparing NB/HDB (right panel) with MS/DB (left panel) E13-E17. Note also an apparent overgrowth at P10. $A$ and $H$, At E13, diffusely immunoreactive profiles are first detected in the intermediate zone of the ventromedial telencephalic wall. $B$ and $I$, At E14, there is an increased staining in the NB region. $C$ and $J$, At E16, immature MS neurons are visible along the midline, and NB/HDB neurons become quite numerous and distinct. $D$ and $K$, At E17, substantial increases in both the neuronal number and neuropil staining are apparent. Scale bar (in $K), 100 \mu \mathrm{m}(A-D, H-K)$. E and $L$, At P1, basal forebrain neurons form well-defined nuclei. Also, extensive dendritic arborization can be appreciated. $F$ and $M$, At P10, the increase in cell size and profuse dendritic arborization make the identification of individual cells difficult, especially in NB/HDB $(M)$. The density of cells and neuropil staining appear even greater at P10 compared with the adult, $G$ and $N$. Scale bar (in $M), 200 \mu \mathrm{m}(E-G, L-M)$.

RI in the perinatal period, a possible explanation may be that antigenic changes in the NGF receptors occur during development such that the epitopes are no longer recognized in mature animals by the monoclonal antibody $192 \mathrm{IgG}$. Alternately, immunocytochemical method may not be sensitive enough to de- tect very low numbers of NGF receptors present in striatal interneurons. Unlike basal forebrain cholinergic neurons, which contain relatively high levels of NGF, and their target areas, which contain the highest levels of both NGF mRNA and NGF protein in the $\mathrm{CNS}$, the adult striatum contains very low levels 

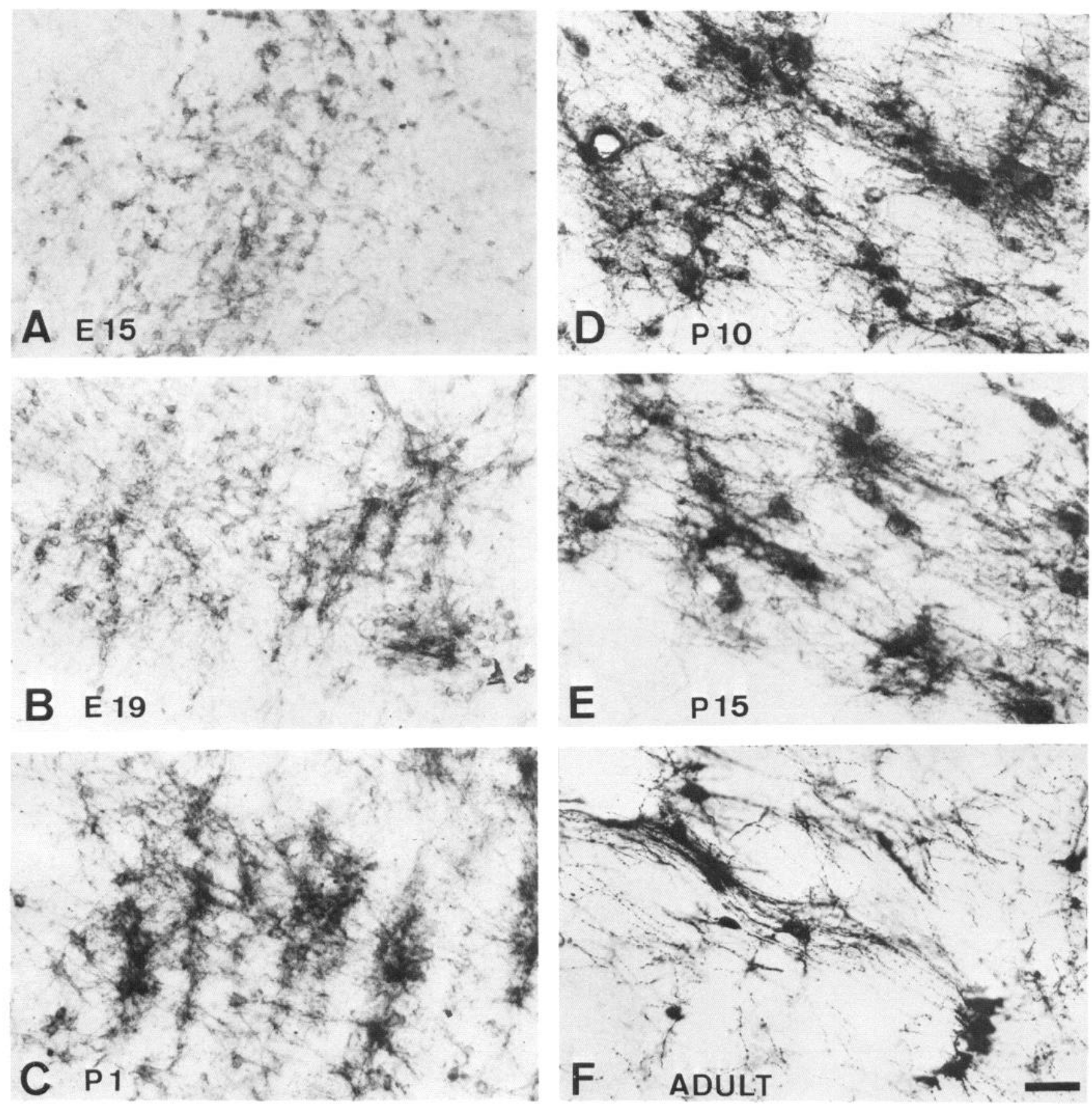

Figure 6. Cellular differentiation of NGF-RI in NB. Horizontal sections through comparable levels at each age. A, E15: Individual immunoreactive cells are discernible and short neurites can be seen. $B$, E19: There is an increase in immunoreactive cell number and neurite staining. $C$, P1: More extensive dendritic growth and an increase in perikaryal size is accompanied by more mature alignment of neurons in the mediolateral axis. $D$, P10, and E, P15: Neuronal and dendritic growth continue and the perikaryal and neuritic arborization increase to an extent greater than that of mature neurons. $F$, While apparently smaller than at P15, each cell soma appears to be more densely immunoreactive and to bear more distinctly stained, beaded dendrites.

of NGF and its mRNA (Korsching et al., 1985; Whittemore et al., 1986). Also, although ChAT induction by exogenous NGF administration in neonatal striatum has been demonstrated both in vivo (Mobley et al., 1985) and in vitro (Martinez et al., 1985), the close proximity of cholinergic neurons of $\mathrm{NB} / \mathrm{DB}$ to the striatum in young rats (see Fig. 4) requires reinspection of these earlier works. Indeed, compared with basal forebrain neurons, striatal interneurons have a narrower period of NGF sensitivity during development (Johnston et al., 1987). Significantly, this time period coincides with the transient expression of NGF-RI in these neurons, as seen in the present study.

\section{Development of NGF-RI basal forebrain neurons}

NGF-RI is first visible at E13 in the caudally located ventrolateral cell group and at E15 in the rostrally located dorsomedial cell group, suggesting that basal forebrain neurons express NGF 

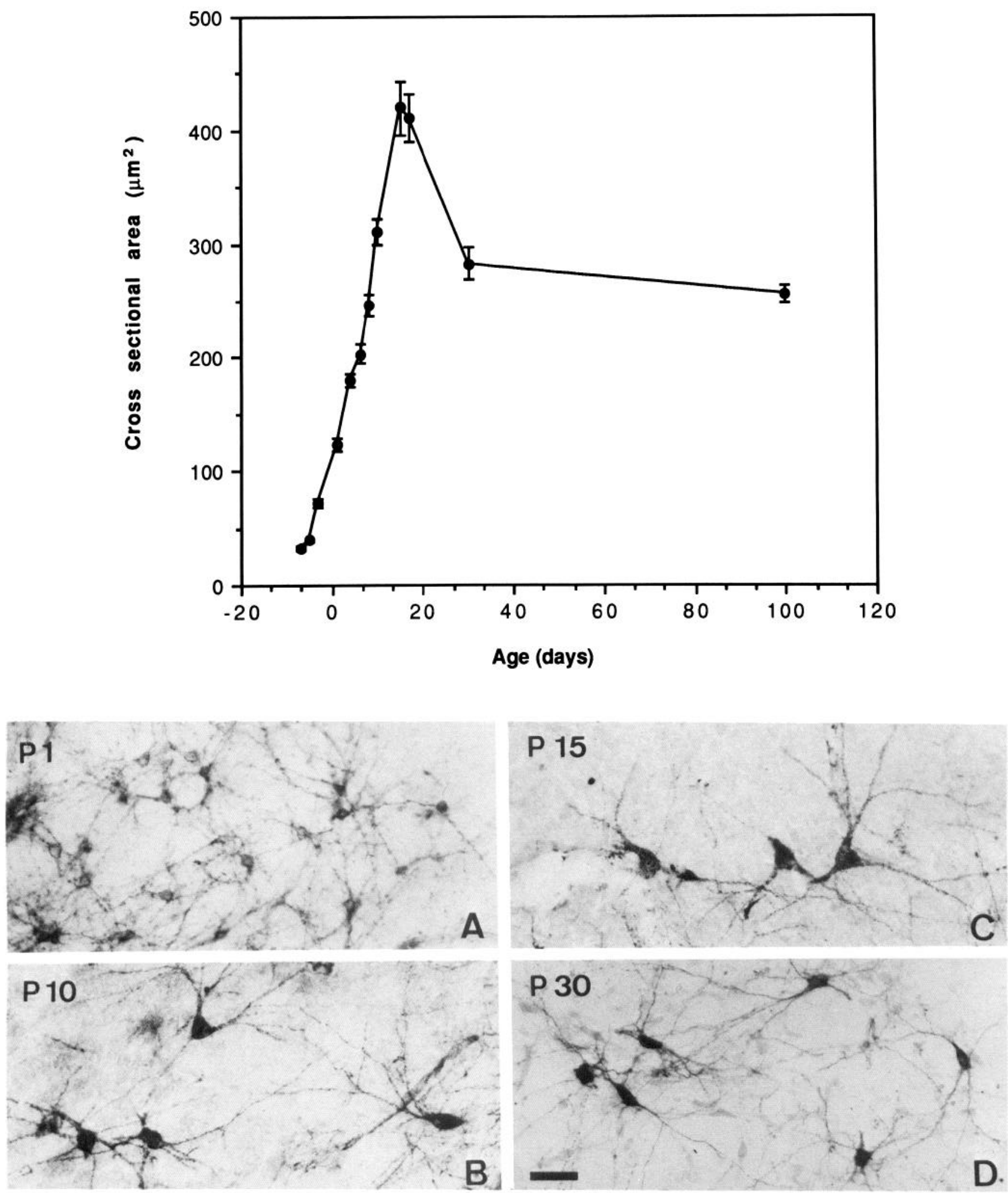

Figure 7. Developmental changes in mean cross-sectional areas ( \pm SEM) of NGF-RI NB neurons. Perikaryal size increases linearly from E15 to P15, reaches almost twice the adult size at P15, and then shrinks to a stable mature size by P30. Quantification of cross-sectional area was done by using IBAS II, computer-assisted, image-based analysis system. $A-D$, Representative cell populations in the coronal section through the substantia innominata region from which measurements of cross-sectional area were made. All figures are at the same magnification. Scale bar, $50 \mu \mathrm{m}$. 

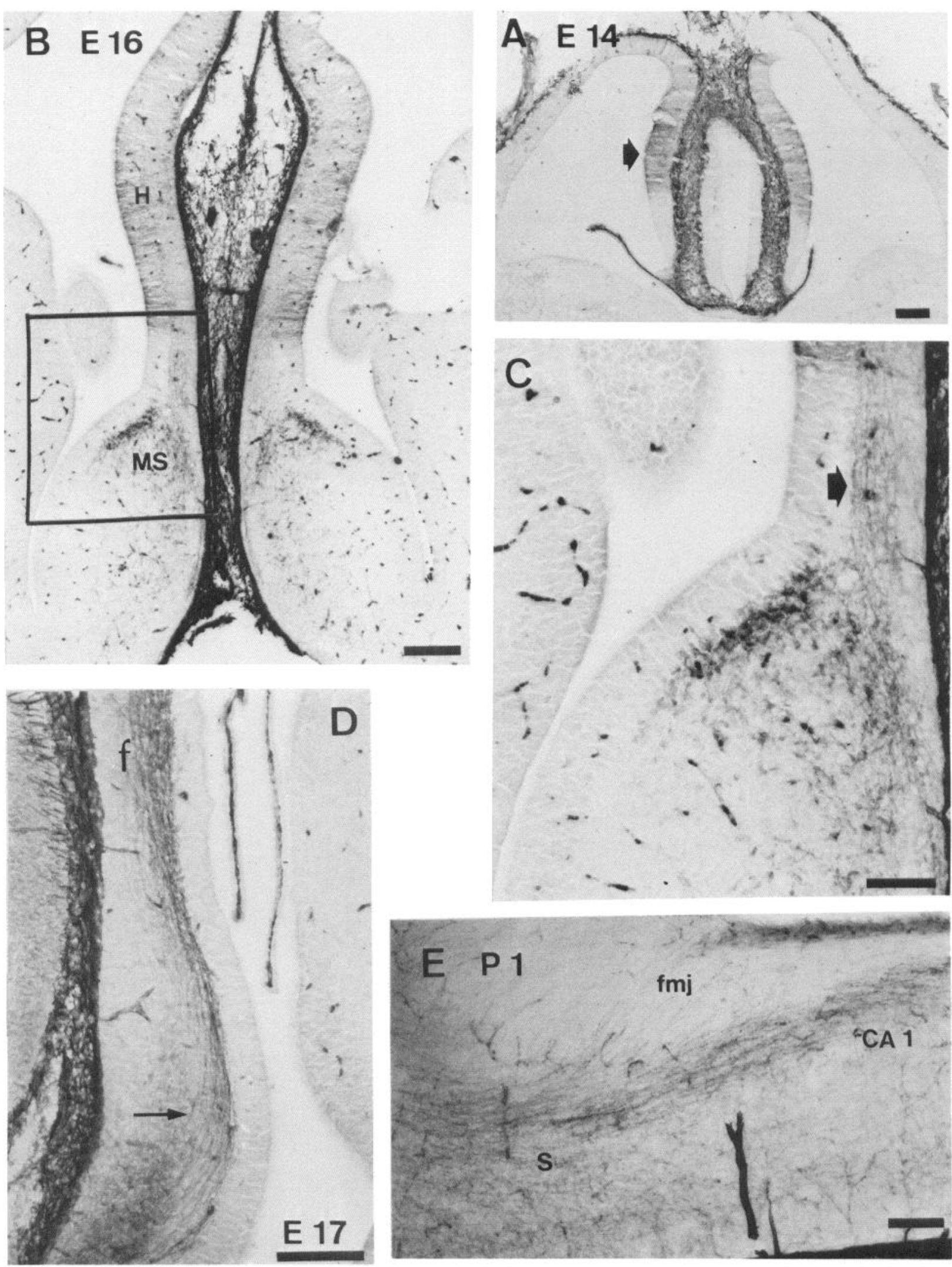

Figure 8. Target arrival of basal forebrain afferents: septohippocampal projection. A, Hippocampal anlage at E14. Arrow points to the radially oriented NGF-RI fibers, which span from ventricular to pial surface. Coronal section. Scale bar, $200 \mu \mathrm{m}$. $B$, At E16, NGF-RI fiber bundles emanating from septum are apparently directed toward hippocampal anlage $(H)$. Note the juxtaposition of the immature septum to the hippocampal anlage at this age. Coronal section. $M S$, medial septum. Scale bar, $200 \mu \mathrm{m}$. C, Higher-magnification view of the boxed area in $B$. Arrow points to the NGF-RI fascicles of axons traversing dorsorostrally from the MS/DB toward the hippocampus. $D$, Horizontal section through hippocampal anlage at E17 showing dense immunoreactivity in the fimbria $(f)$ and the fibers entering immature hippocampus in a fanning pattern $(a r r o w)$. Scale bar, $100 \mu \mathrm{m}$. E, Coronal section through caudal hippocampus at P1. NGF-RI septal axons can be seen at this level as they turn around the forcep major of the corpus callosum $(\mathrm{fmj})$ to enter subiculum $(s)$ and CAl hippocampal subfields. Scale bar, $100 \mu \mathrm{m}$. 

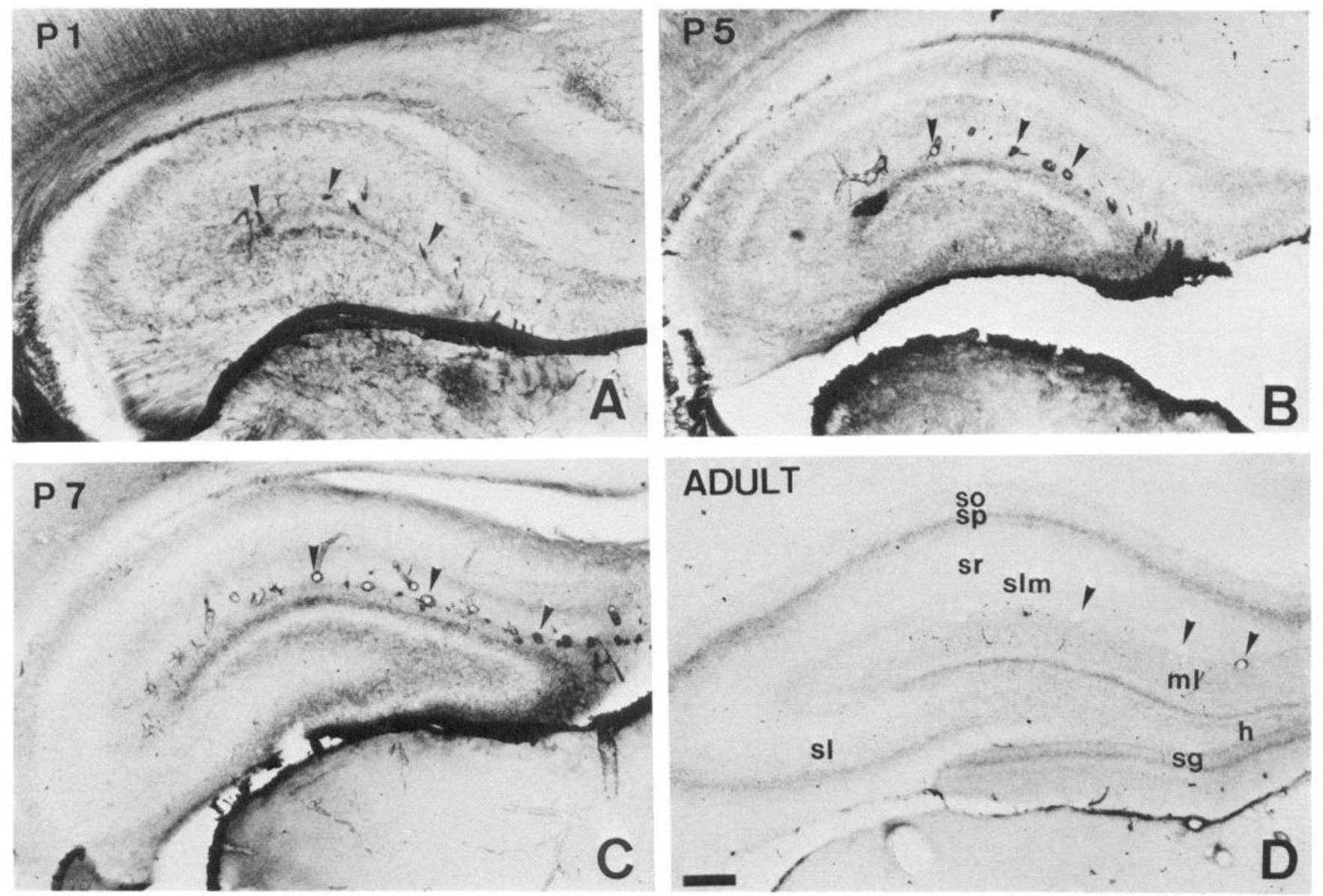

Figure 9. Developmental changes in the lamination pattern of NGF-RI septal axons in the hippocampus. $A$, At P1, NGF-RI is diffusely associated with dendritic zones around the wide band of cellular layers which are almost devoid of immunoreactive fibers. Note an intensification of staining at the lateral margin of suprapyramidal limb of the dentate gyrus. $B$, At P5, cell layers clear of axonal termination are more prominent. $C$, At P7, fiber staining around the infrapyramidal limb of the dentate gyrus becomes visible, and the hilus contains an increased amount of immunoreactivity. $D$, In mature hippocampus, the NGF-RI axon terminals are tightly associated with narrow cellular zones. Arrowheads in each figure mark the immunoreactive blood vessels which align the invaginated hippocampal fissure. $h$, hilus fasciae denatae; $m l$, stratum moleculare; $s g$, stratum granulosum; $s l$, stratum lucidum of $\mathrm{CA} 3 ; s l m$, stratum lacunosum moleculare; $s o$, stratum oriens; $s p$, stratum pyramidale; $s r$, stratum radiatum. Scale bar, $200 \mu \mathrm{m}$.

receptor shortly after they become postmitotic (Bayer, 1979, 1985 ) and that the initial appearance of NGF receptor follows the same caudal-to-rostral gradient as ${ }^{3} \mathrm{H}$-thymidine labeling (Semba and Fibiger, 1988). Thus, it appears unlikely that the initial expression of NGF receptor is induced by target-derived NGF. Rather, NGF receptors appear concurrently with neurogenesis in the basal forebrain, indicating that this receptor for a trophic and survival factor may be one of the first phenotypically characteristic molecules to be expressed in cholinergic neurons, preceding transmitter-specific markers by several days (Milner et al., 1983; Sofroniew et al., 1987). Importantly, however, NGF is present in the target issue before the arrival of afferents from basal forebrain neurons, as an adult level of NGF is detected in the telencephalic region (which includes both cortex and hippocampus) by E14 (Auburger et al., 1987). Thus, the expression of NGF receptor on growing axons at E15, the proximity of the target to the source of innervation at the time of initial axonal outgrowth, the presence of NGF within the target field prior to the arrival of cholinergic fibers, and the localization of both NGF (Lakshmanan et al., 1986) and NGF receptors (Szutowicz et al., 1976) to synaptosomal fractions in developing brain, together support the hypothesis that NGF may act as a chemoattractant to guide the elongation of cholinergic fibers toward synaptic targets during CNS embryogenesis.

Between E13 and E17, the number of NGF-RI neurons increases without an appreciable change in cell soma size. After proliferation ceases at E17, the cross-sectional area of NGF-RI perikarya increases rapidly, reaches a peak by $\mathrm{P} 15$, and then abrubtly drops to nearly the adult value by P30. Thus, there is a period of hypertrophy during development, when the basal forebrain neurons reach almost twice the adult size, before they shrink to a stable mature size. A very similar profile of a developmental increase and subsequent decrease in cell soma size has been reported for ChAT-positive basal forebrain neurons in the rat (Sofroniew et al., 1987). Since NGF causes hypertrophy of sympathetic neurons (Levi-Montalcini and Booker, 1960; Hendry and Campbell, 1976), it may not be a coincidence that the peak in the NGF-RI neuronal size is paralleled by a steep increase in production of NGF in CNS target areas during the third postnatal week (Large et al., 1986; Whittemore et al., 1986; Auburger et al., 1987). Also, NGF promotes the survival of responsive neurons during restricted periods of their develop- 

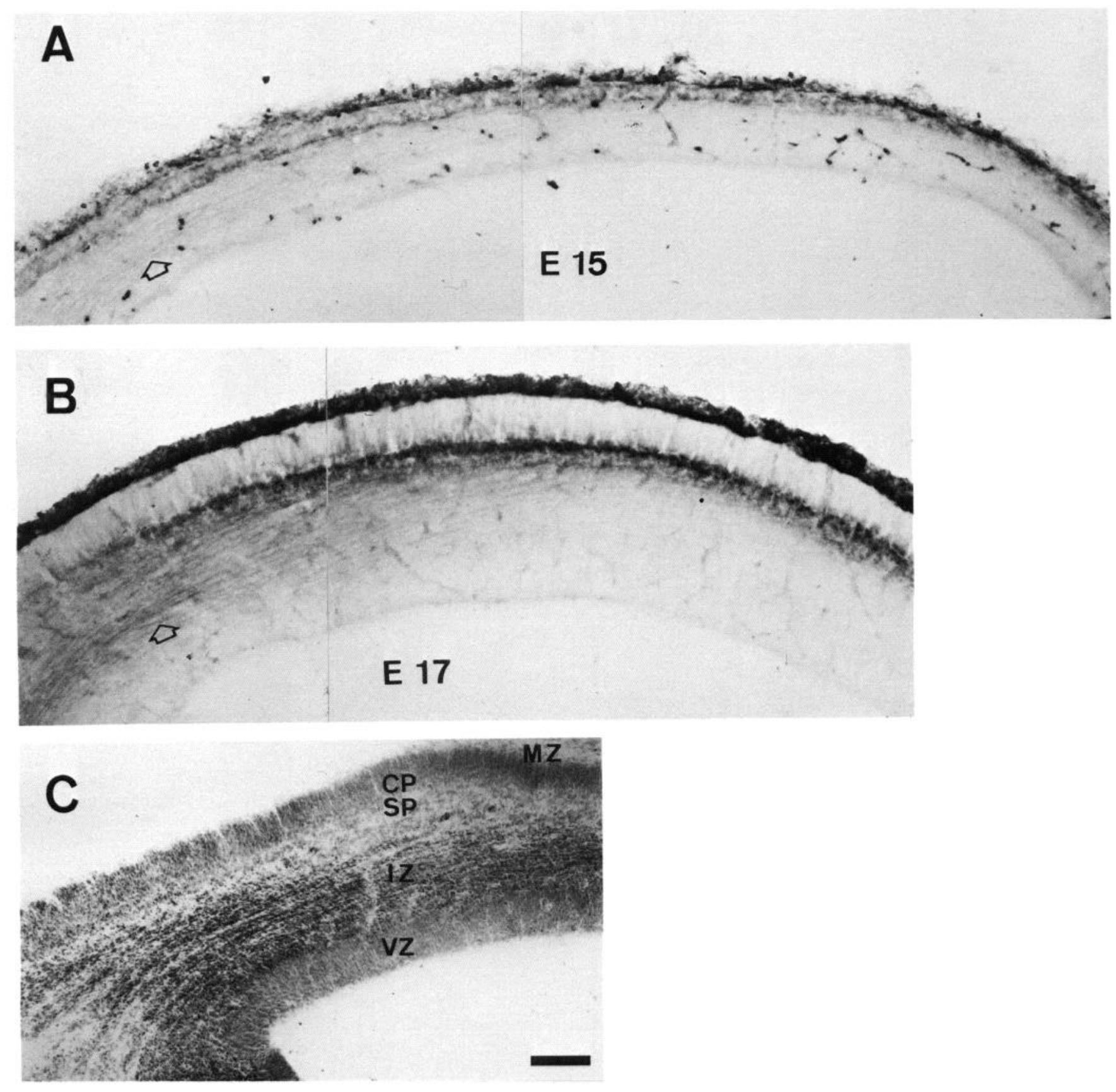

Figure 10. Transient expression of NGF-RI associated with cortical afferents, subplate, and radially oriented fiber projections. A, Arrival of NB afferents (arrow) and the emergence of the cortical plate at E15. Note the NGF-RI in the marginal and subplate zones and the absence of staining in the incipient cortical plate to the left of the photomicrograph. As cortical plate development starts ventrolaterally and proceeds dorsomedially, the densely immunoreactive bands merge and NGF-RI becomes limited to the marginal zone toward the occipital pole (at right of photomicrograph). $B$, Increased afferent arrival and accumulation within the intermediate zone underneath the densely immunoreactive subplate at E17. Marginal zone is obscured by darkly stained pial matter. Note the absence of ingrowth of NGF-RI fibers into the cortical plate. $C$, Cresyl violet-stained section at a comparable level as $A$ and $B$ to show histological composition of striate cortex at $\mathrm{E} 16 . C P$, cortical plate; $I Z$, intermediate zone; $M Z$, marginal zone; $S P$, subplate; $V Z$, ventricular zone. Scale bar, $100 \mu \mathrm{m}(A-C)$. $D$, With the continued addition of neurons into the cortical plate, intensely immunoreactive subplate zone moves closer to the ventricular zone. Cortical afferents (arrow) are still arrested underneath the subplate. $E$, At P1, radially oriented NGF-RI emanates from densely stained subplate and extends up toward the pial surface. Arrow points to the dense

ment in the PNS (e.g., Hamburger et al., 1981). It remains to be shown if this ubiquitous phenomenon of target-dependent cell death also occurs during the normal development of NGFsensitive neurons in the CNS, and if it can be prevented by NGF.
Concomitant with the increase in perikaryal size, there is profuse dendritic growth during the first 3 postnatal weeks. An extensive neuritic plexus is first appreciable near birth, at the time the lamination pattern is being established in the hippocampal terminal fields by NGF-RI septal axons. Also, the peaks 

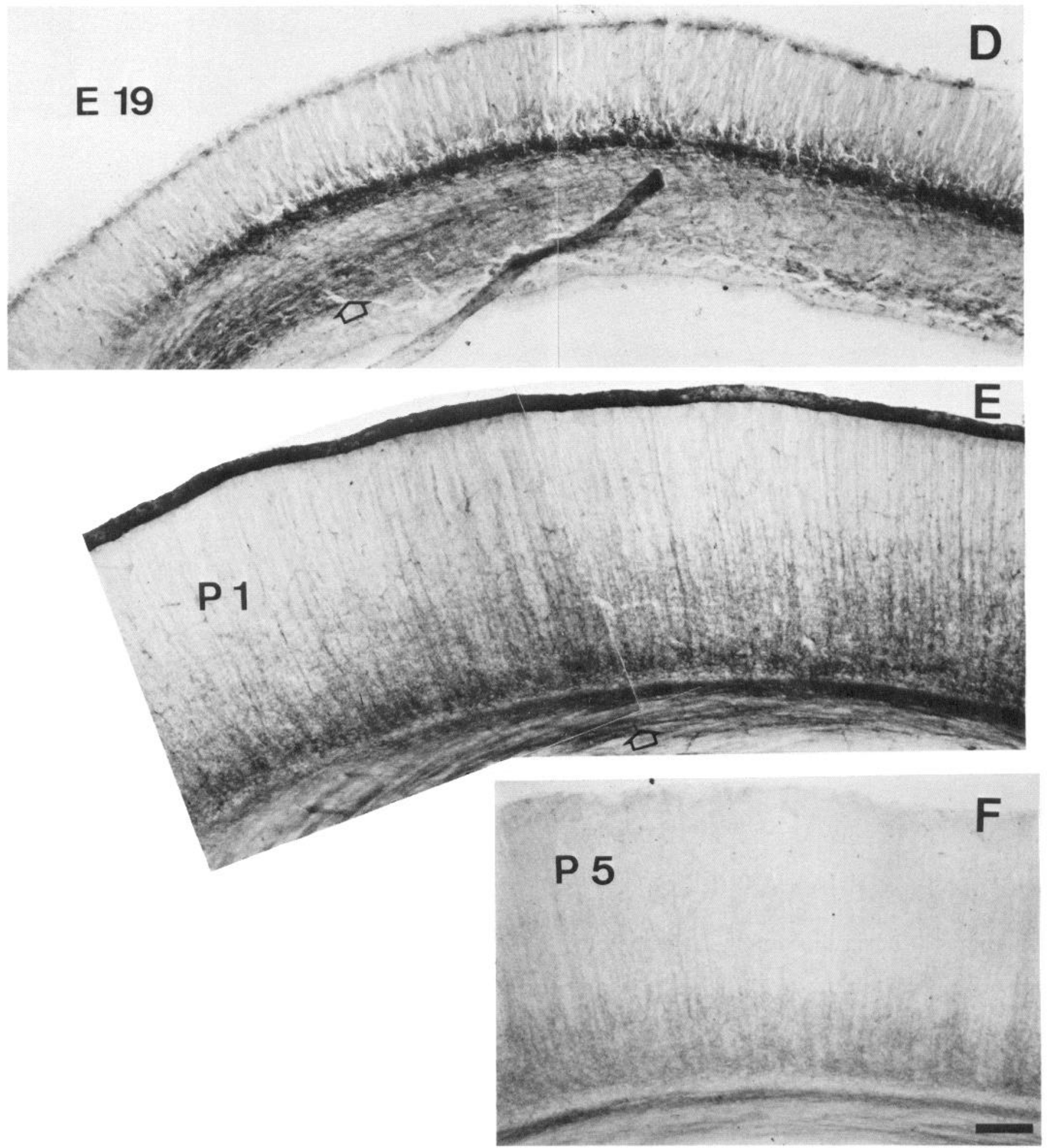

band of immunoreactivity within the intermediate zone formed by tangentially oriented thalamocortical afferents. $F$, Marked decrease in both radial and thalamocortical staining at $\mathrm{P} 5$. Scale bar, $100 \mu \mathrm{m}(D-F)$.

in the NGF-RI perikaryal size and neuritic growth correspond to the period of explosive synaptogenesis in rat dentate gyrus and cortex (Crain et al., 1973; Sorimachi and Kataoka, 1975; Shelton et al., 1979). On the other hand, the decrease in cell soma size by P30 correlates with the establishment of a mature hippocampal terminal field and diminished intensity and amount of fiber staining in cortex, suggesting that synaptic rearrangement and collateral withdrawal (Cowan et al., 1984) may be involved in the observed cell shrinkage in maturity. Retrogradely transported NGF, therefore, may not only affect chemical 


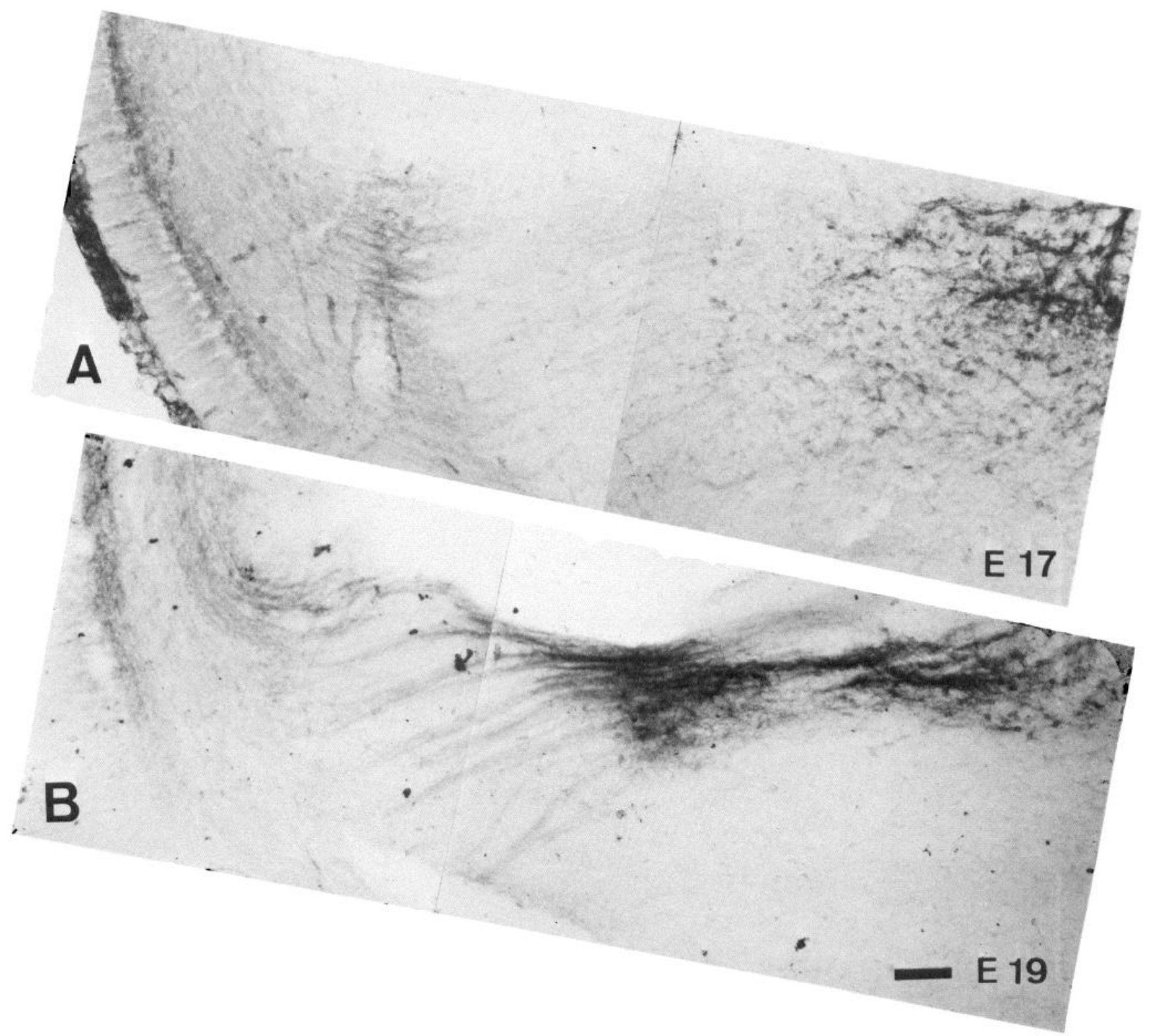

Figure 11. Target arrival of basal forebrain afferents: basalocortical projection. A, At E17, NGF-RI axonal bundles emanate from basalis neurons and sweep laterally through the ventral part of the caudate-putamen to enter the developing cortex. $B$, Fasciculation of densely immunoreactive fibers at E19.

differentiation (Large et al., 1986), but may also stimulate growth and morphological differentiation of basal forebrain cholinergic neurons.

\section{Target arrival of basal forebrain afferents}

The outgrowth of axons from MS/DB to the hippocampal anlage can be followed by the successive advance of NGF-RI in the supracallosal stria, dorsal fornix, and fimbria. The first definitive axonal-type staining is first seen in the marginal zone (future stratum radiatum) above the cortical plate (stratum pyramidale) at E17. This is $3 \mathrm{~d}$ earlier for the septal axons to have entered the hippocampus than previously found using traditional tracttracing techniques, presumably due to the limitations of placing embryonic injections (Crutcher, 1982; Milner et al., 1983), and substantially earlier than the expression of $\mathrm{AChE}$ activity, which is first detected biochemically on P1 (Loy and Sheldon, 1987) and seen histochemically on P3 (Matthews et al., 1974; Milner et al., 1983).

Thus, NGF-R-bearing axons from the basal forebrain neurons may be one of the earliest fiber systems to innervate the neocortex and hippocampus. The noradrenergic fibers arising from the locus coeruleus can be seen no earlier than E18 both in the neocortex (Levitt and Moore, 1979) and in the CA1 and CA3 hippocampal subfields and the anlage of the dentate gyrus (Loy and Moore, 1979). The entorhinal and commissural/associational afferent systems appear to arrive in the hippocampal formation even later in the perinatal period (Loy et al., 1977; Loy, 1980). In the cortex, the axons of geniculate neurons invade the 

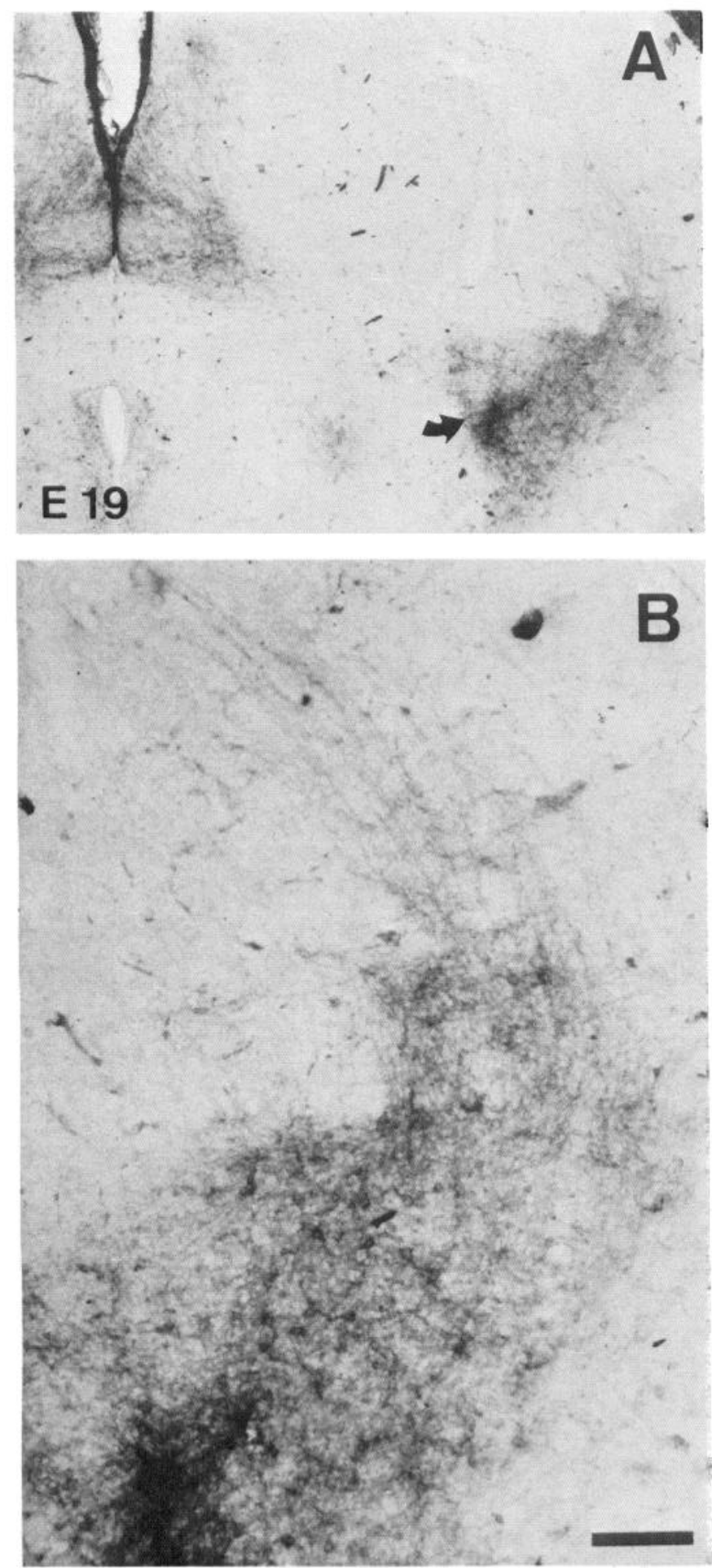
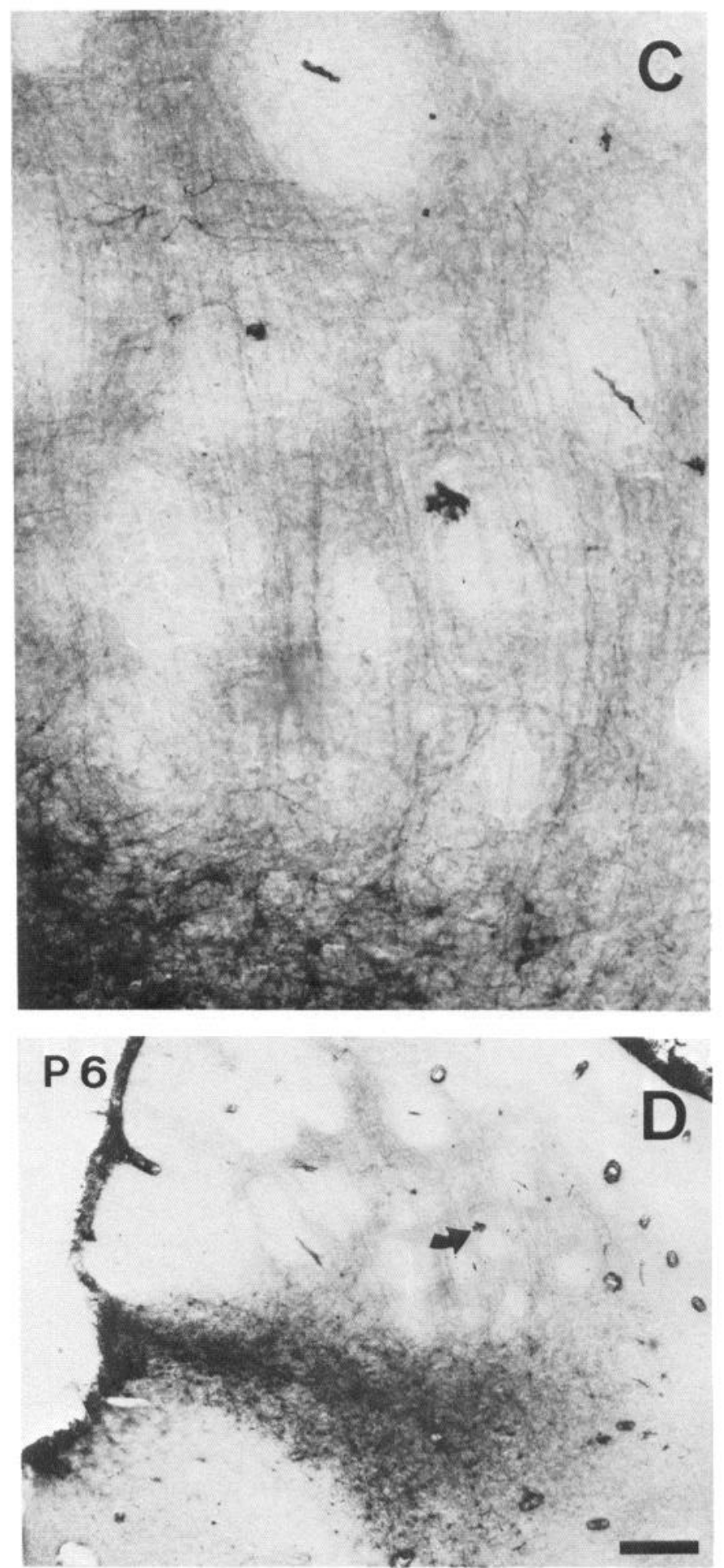

Figure 12. Profuse axonal outgrowth from basal forebrain neurons. $A$, Horizontal section at E19 shows fibers from NB neurons directly entering paleocortical areas. Arrow points to a landmark to help locate the higher-magnification view in $B$. Scale bar in $B, 100 \mu \mathrm{m}$, also applies to $C$. $C$, Higher magnification view of $D$. Note highway of fiber path around islands of hollow stain-free areas. $D$, Horizontal section at P6 shows profuse axonal growth from HDB entering piriform cortical area. Arrow points to a landmark. Scale bar in $D, 200 \mu \mathrm{m}$, also applies to $A$.

telencephalon on E16 and run in the intermediate zone just below the cortical plate to reach the visual cortex on E18 (Lund and Mustari, 1977). Thus, basal forebrain afferent fibers, which invade the target areas at E15, arrive in the neocortex and hippocampus during the earliest period of cell proliferation, mi- gration, and differentiation, and would be in a position to influence these events, as previously proposed for early-arriving monoamines (e.g., Lauder and Krebs, 1978). Indeed, destruction of the basal forebrain nuclei at birth induces abnormal cortical cytoarchitectonic patterns (Hohmann et al., 1988), sup- 
porting the hypothesis that cholinergic afferents from basal forebrain neurons are important for cortical morphogenesis and maturation.

\section{Transient expression of NGF-RI during neuronal proliferation and afferent arrival}

In both the hippocampus and neocortex, endogenous NGF-RI appears transiently in several regions. From the time of its first appearance at E15, the subplate zone contains dense NGF-RI. Postnatally, during the transition period between subplate staining and basal forebrain terminal staining, NGF-RI is also present in radially oriented fibers, emanating from the subplate and spanning the whole thickness of the cortical surface. Finally, in the hippocampal anlage, radially oriented fibers extend from the ventricular zone to the pial surface at E14-E15, before the emergence of the dentate gyrus.

The cellular or extracellular localization and the source of the intracortical NGF receptor are unclear. Since the distribution and timing of the appearance of NGF-RI in the marginal and subplate zone corresponds to that of early-arriving afferent axons, NGF receptors in these areas may be associated exclusively with the ingrowing basal forebrain fibers. Alternately, glial cells may be locally producing NGF receptors (Marchetti et al., 1987). While the relatively late appearance plus the characteristic fine staining are not similar to vimentin-positive rodent radial glia (Pixley and deVellis, 1984), Cooper and his colleagues (1987) have detected NGF-RI in the barrel subfield of the somatosensory cortex in conjunction with GFAP-positive immature glia during early postnatal development, supporting a glial association of NGF receptor. Since sensory neurons and Schwann cells co-express NGF receptors on their surfaces at the time when neuron-glia cell interaction is initiated (Zimmermann and Sutter, 1983), transiently induced NGF receptors in the radially oriented glia may play a role in forming the migratory pathway for the ingrowing cortical afferents and help the establishment of proper synaptic contacts.

A role in guiding synaptogenesis is also suggested by the detection of NGF receptor in the marginal and subplate zoncs of developing neocortex at the time of cortical plate formation and NB afferent arrival. NGF-RI in the subplate zone gradually diminishes during the first postnatal week, at the time when NB afferents invade the cortex and form specific axon terminals, and it is absent in the adult. The subplate zone contains many synapses and a substantial number of early-generated transient cells, which may act as temporary targets for ascending afferent systems to the cerebral cortex (Marin-Padilla, 1978; Kostovic and Rakic, 1980). In this context, it is interesting to note that basal forebrain afferents accumulate in the intermediate zone, apparently arrested at the densely NGF-RI subplate before they enter the cortex. This "waiting" is not unique to basal forebrain afferents but also occurs with 2 principal extrinsic afferent fiber systems to the cortex, the thalamocortical and the callosal (Wise and Jones, 1978; Shatz and Luskin, 1986). These fibers grow very early towards their cortical targets but accumulate over a protracted period in the intermediate zone beneath the cortical plate before resuming growth and entering the cortex. The nature of the signaling mechanism is unclear; it is, however, apparently a differential one, since thalamic fibers grow into the cortex before commissural fibers (Wise and Jones, 1978). It is tempting to speculate that transient expression of NGF receptor in the subplate and concomitant local accumulation of NGF in this region may provide a stop signal to ingrowing NB fibers; re- sumed growth and innervation of proper target sites in the cortex may occur subsequent to the disappearance of NGF receptors and the dissipation of NGF. The protracted waiting of cortical afferents in the subplate zone may result from the temporal mismatch between the time of arrival of afferents and the maturation of target sites (Shatz and Luskin, 1986). The basal forebrain afferents may necessarily be guided by the target-derived NGF at the stage when the cortex is still immature and the distance traveled by the growing axon is sufficiently short. Once axons arrive, NGF and NGF receptor may then be working in concert to act as a temporary target for these early basal forebrain afferents until cortical neurons achieve sufficient postmigratory maturity. It will be important to know if the induction of transient NGF receptor in the subplate zone is accompanied by local accumulation of NGF. NGF is present in high concentrations in the rat brain as early as E14 (Auburger et al., 1987); it remains to be determined if NGF colocalizes with NGF receptor in the subplate zone at the time of afferent arrival and if NGF later disperses to the entire cortex in correlation with the laminar pattern of cholinergic terminals.

\section{References}

Armstrong, D. M., C. B. Saper, A. I. Levey, B. H. Wainer, and R. D. Terry (1983) Distribution of cholinergic neurons in rat brain: Demonstrated by the immunocytochemical localization of choline acetyltransferase. J. Comp. Neurol. 216: 53-68.

Auburger, G., R. Heumann, R. Hellweg, S. Korsching, and H. Thoenen (1987) Developmental changes of nerve growth factor and its mRNA in the rat hippocampus: Comparison with choline acetyltransferase. Dev. Biol. 120: 322-328.

Bayer, S. A. (1979) The development of septal region in the rat. 1. Neurogenesis examined with ${ }^{3} \mathrm{H}$-thymidine autoradiography. J. Comp. Neurol. 183: 89-106.

Bayer, S. A. (1985) Neurogenesis of the magnocellular basal telencephalic nuclci in the rat. Int. J. Dev. Neurosci. 3: 229-243.

Bigl, V., N. J. Woolf, and L. L. Butcher (1982) Cholinergic projections from the basal forebrain to frontal, parietal, temporal, occipital and cingulate cortices: A combined fluorescent tracer and acetylcholinesterase analysis. Brain Res. Bull. 8: 727-749.

Buck, C. R., H. J. Martinez, I. B. Black, and M. V. Chao (1987) Developmentally regulated expression of the nerve growth factor receptor gene in the periphery and brain. Proc. Natl. Acad. Sci. USA 84: 3060-3063.

Campenot, R. B. (1977) Local control of neurite development by nerve growth factor. Proc. Natl. Acad. Sci. USA 74: 4516-4519.

Chandler, C. E., L. M. Parsons, M. Hosang, and E. M. Shooter (1984) A monoclonal antibody modulates the interaction of nerve growth factor with PC12 cells. J. Biol. Chem. 259: 6882-6889.

Cooper, N. G. F., J. B. Schweitzer, and D. A. Steindler (1987) A monoclonal antibody directed against the nerve growth factor receptor delineates the barrel subfield in developing rat somatosensory cortex. Soc. Neurosci. Abstr. 13: 254.

Cowan, W. M., J. W. Fawcett, D. D. M. O'Leary, and B. B. Stanfield (1984) Regressive events in neurogenesis. Science 225: 1258-1265.

Crain, B., C. Cotman, D. Taylor, and G. Lynch (1973) A quantitative electron microscopic study of synaptogenesis in the dentate gyrus of the rat. Brain Res. 63: 195-204.

Crutcher, K. A. (1982) Development of the rat septohippocampal projections: A retrograde fluorescent tracer study. Dev. Brain Res. 3: 145-150.

Dawbarn, D., S. J. Allen, and F. M. Semenenko (1988) Immunohistochemical localization of $\beta$-nerve growth factor receptors in the forebrain of the rat. Brain Res. 440: 185-189.

Gähwiler, B. H., and F. Hefti (1984) Guidance of acetylcholinesterasecontaining fibres by target tissue in co-cultured brain slices. Neuroscience 13: 681-689.

Gähwiler, B. H., A. Enz, and F. Hefti (1987) Nerve growth factor promotes development of the rat septohippocampal cholinergic projection in vitro. Neurosci. Lett. 75: 6-10.

Gnahn, H., F. Hefti, R. Heumann, M. E. Schwab, and H. Thoenen 
(1983) NGF-mediated increase of choline acetyltransferase (ChAT) in the neonatal rat forebrain: Evidence for a physiological role of NGF in the brain? Dev. Brain Res. 9: 45-52.

Gundersen, R. W., and J. N. Barrett (1979) Neuronal chemotaxis: Chick dorsal-root axons turn toward high concentrations of nerve growth factor. Science 206: 1079-1080.

Hamburger, V. (1934) The effects of wing bud extirpation on the development of the central nervous system in chick embryos. J. Exp. Zool. 68: 449-494.

Hamburger, V. (1939) Motor and sensory hyperplasia following limbbud transplantations in chick embryos. Physiol. Zool. 12: 268-284.

Hamburger, V., J. K. Brunso-Bechtold, and J. W. Yip (1981) Neuronal death in the spinal ganglia of the chick embryo and its reduction by nerve growth factor. J. Neurosci. 1: 60-71.

Hancock, J. C. (1982) A serotonin-like immunoreactive fiber system in the dorsal columns of the spinal cord. Neurosci. Lett. 31:247-252.

Hefti, F., J. Hartikka, F. Eckenstein, H. Gnahn, R. Heumann, and M. Schwab (1985) Nerve growth factor increases choline acetyltransferase but not survival or fiber outgrowth of cultured fetal septal cholinergic neurons. Neuroscience 14: 55-68.

Hendry, I. A., and J. Campbell (1976) Morphometric analysis of rat superior cervical ganglion after axotomy and nerve growth factor treatment. J. Neurocytol. 5: 351-360.

Herrup, K., and E. M. Shooter (1975) Properties of the $\beta$-nerve growth factor receptor in development. J. Cell Biol. 67: 118-125.

Hohmann, C. F., A. R. Brooks, and J. T. Coyle (1988) Neonatal lesions of the basal forebrain cholinergic neurons result in abnormal cortical development. Dev. Brain Res. 42: 253-264.

Johnston, M. V., J. L. Rutkowski, B. H. Wainer, J. B. Long, and W. C. Mobley (1987) NGF effects on developing forebrain cholinergic neurons are regionally specific. Neurochem. Res. 12: 985-994.

Kordower, J. H., R. T. Bartus, M. Bothwell, G. Schatteman, and D. M. Gash (1988) Nerve growth factor receptor immunoreactivity in the non-human primate (Cebus apella): Distribution, morphology and colocalization with cholinergic enzymes. J. Comp. Neurol. 277: 465486.

Korsching, S., G. Auburger, R. Heumann, J. Scott, and H. Thoenen (1985) Levels of nerve growth factor and its mRNA in the central nervous system of the rat correlate with cholinergic innervation. EMBO J. 4: 1389-1393.

Kostovic, I., and P. Rakic (1980) Cytology and time of origin of interstitial neurons in the white matter in infant and adult human and monkey telencephalon. J. Neurocytol. 9:219-242.

Lakshmanan, J., M. E. Weischel, Jr., R. Tarris, and D. A. Fisher (1986) $\beta$-Nerve growth factor in developing mouse cerebral cortical synaptosomes: Measurement by competitive radioimmunoassay and bioassay. Ped. Res. 20: 391-397.

Lance-Jones, C., and L. Landmesser (1980) Motoneuron projection patterns in chick hind limb following partial reversals of the spinal cord. J. Physiol. (Lond.) 302: 581-602.

Large, T. H., S. C. Bodary, D. O. Clegg, G. Weskamp, U. Otten, and L. F. Rcichardt (1986) Ncrve growth factor genc cxpression in the developing rat brain. Science 234: 352-355.

Lauder, J. M., and H. Krebs (1978) Serotonin as a differentiation signal in early neurogenesis. Dev. Neurosci. 1: 15-30.

Levi-Montalcini, R., and R. Booker (1960) Excessive growth of the sympathetic ganglia evoked by a protein isolated from mouse salivary glands. Proc. Natl. Acad. Sci. USA 46: 373-383.

Levitt, R., and R. Y. Moore (1979) Development of the noradrenergic innervation of neocortex. Brain Res. 162: 243-259.

Loy, R. (1980) Development of afferent lamination in Ammon's horn of the rat. Anat. Embryol. 159: 257-275.

Loy, R., and R. Y. Moore (1979) Ontogeny of the noradrenergic innervation of the rat hippocampal formation. Anat. Embryol. 157: 243-253.

Loy, R., and R. A. Sheldon (1987) Sexually dimorphic development of cholinergic enzymes in the rat septohippocampal system. Dev. Brain Res. 34: 156-160.

Loy, R., G. Lynch, and C. W. Cotman (1977) Development of afferents lamination in the fascia dentata of the rat. Brain Res. 121: 229-243.

Lund, R. D., and M. J. Mustari (1977) Development of the geniculocortical pathway in rats. J. Comp. Neurol. 173: 289-305.

Luskin, M. B., and C. J. Shatz (1985) Studies of the earliest generated cells of the cat's visual cortex: Cogeneration of subplate and marginal zones. J. Neurosci. 5: 1062-1075.

Marchetti, D., R. W. Stach, R. Saneto, J. deVellis, and J. R. Perez-
Polo (1987) Binding constants of soluble NGF-receptors in rat oligodendrocytes and astrocytes in culture. Biochem. Biophysic. Res. Commun. 147: 422-427.

Marin-Padilla, M. (1978) Dual origin of the mammalian neocortex and evolution of the cortical plate. Anat. Embryol. 152: 109-126.

Martinez, H. J., C. F. Dreyfus, G. M. Johakait, and I. B. Black (1985) Nerve growth factor promotes cholinergic development in brain striatal cultures. Proc. Natl. Acad. Sci. USA 82: 7777-7781.

Matthews, D. A., J. V. Nadler, G. S. Lynch, and C. W. Cotman (1974) Development of cholinergic innervation in the hippocampal formation of the rat. I. Histochemical demonstration of acetylcholinesterase activity. Dev. Biol. 36: 130-141.

Milner, T. A., R. Loy, and D. G. Amaral (1983) An anatomical study of the development of the septo-hippocampal projection in the rat. Dev. Brain Res. 8: 343-371.

Mobley, W. C., J. L. Rutkowski, G. I. Tennekoon, K. Buchanan, and M. V. Johnston (1985) Choline acetyltransferase activity in striatum of neonatal rats increased by nerve growth factor. Science 229:284 287.

Mobley, W. C., J. L. Rutkowski, G. I. Tennekoon, J. Gemski, K. Buchanan, and M. V. Johnston (1986) Nerve growth factor increases choline acetyltransferase activity in developing basal forebrain neurons. Mol. Brain Res. 1: 53-62.

Pixley, S. K., and J. deVellis (1984) Transition between immature radial glia and mature astrocytes studied with a monoclonal antibody to Vimentin. Dev. Brain Res. 15: 201-209.

Raivich, G., and G. W. Kreutzberg (1987) The localization and distribution of high affinity $\beta$-nerve growth factor binding sites in the central nervous system of the adult rat. A light microscopic autoradiographic study using [ $\left.{ }^{125} \mathrm{I}\right] \beta$-nerve growth factor. Neuroscience 20 : 23-36.

Richardson, P. M., V. M. K. Verge Issa, and R. J. Riopelle (1986) Distribution of neuronal receptors for nerve growth factor in the rat. J. Neurosci. 6: 2312-2321.

Satoh, K., D. M. Armstrong, and H. C. Fibiger (1983) A comparison of distribution of central cholinergic neurons as demonstrated by acetylcholinesterase pharmacohistochemistry and choline acetyltransferase immunohistochemistry. Brain Res. Bull. 11: 693-720.

Schatteman, G. C. L. Gibbs, A. A. Lanahan, P. Claude, and M. Bothwell (1988) Expression of NGF receptor in the developing and adult primate central nervous system. J. Neurosci. 8: 860-873.

Semba, K., and H. C. Fibiger (1988) Time of origin of cholinergic neurons in the rat basal forebrain. J. Comp. Neurol. 269: 87-95.

Shatz, C. J., and M. B. Luskin (1986) The relationship between the geniculocortical afferents and their cortical target cells during development of the cat's primary visual cortex. J. Neurosci. 6: 3655-3668.

Shelton, D. L., J. V. Nadler, and C. W. Cotman (1979) Development of high affinity choline uptake and associated acetylcholine synthesis in the rat fascia dentata. Brain Res. 163: 263-275.

Sofroniew, M. V., R. C. A. Pearson, and T. P. S. Powell (1987) The cholinergic nuclei of the basal forebrain of the rat: Normal structure, development and experimentally induced degeneration. Brain Res. 411: 310-331.

Sorimachi M., and K. Kataoka (1975) High affinity choline uptake: An early index of cholinergic innervation in rat brain. Brain Res. 94: 325-336.

Sperry, R. W. (1963) Chemoaffinity in the orderly growth of nerve fiber patterns and connections. Proc. Natl. Acad. Sci. USA 50:703710 .

Springer, J. E., S. Koh, M. W. Tayrien, and R. Loy (1987) Basal forebrain magnocellular neurons stain for nerve growth factor receptor: Correlation with cholinergic cell bodies and effects of axotomy. J. Neurosci. Res. 17: 111-118.

Stensaas, L. J. (1967) The development of hippocampal and dorsolateral pallial regions of the cerebral hemisphere in fetal rabbits. I. Fifteen millimeter stage, spongioblast morphology. J. Comp. Neurol. 129: 59-70.

Szutowicz, A., W. A. Frazier, and R. A. Bradshaw (1976) Subcellular localization of nerve growth factor receptor. Thirteen-day chick embryo brain. J. Biol. Chem. 251: 1516-1523.

Taniuchi, M., and E. M. Johnson, Jr. (1985) Characterization of the binding properties and retrograde axonal transport of a monoclonal antibody directed against the rat nerve growth factor receptor. J. Cell Biol. 101: 1100-1106.

Thoenen, H., and Y.-A. Barde (1980) Physiology of nerve growth factor. Physiol. Rev. 60: 1284-1335. 
Whittemore, S. R., T. Ebendal, L. Lårkfors, L. Olson, A. Seiger, I. Strømberg, and H. Persson (1986) Developmental and regional expression of $\beta$-nerve growth factor messenger RNA and protein in the rat central nervous system. Proc. Natl. Acad. Sci. USA 83: 817821.

Wise, S. P., and E. G. Jones (1978) Developmental studies of thalamocortical and commissural connections in the rat somatic sensory cortex. J. Comp. Neurol. 175: 187-208.

Yan, Q., and E. M. Johnson, Jr. (1987) A quantitative study of the developmental expression of nerve growth factor (NGF) receptor in rats. Dev. Biol. 121: 139-148.

Yan, Q., and E. M. Johnson, Jr. (1988) An immunohistochemical study of the nerve growth factor receptor in developing rats. J. Neurosci. 8: 3481-3498.

Zimmermann, A., and A. Sutter (1983) Beta-nerve growth factor (NGF) receptors on glial cells. Cell-cell interaction between neurons and Schwann cells in cultures of chick sensory ganglia. EMBO J. 2: 879885 . 